\title{
Evolutionary unique mechanistic framework of clathrin-mediated endocytosis in plants
}

Madhumitha Narasimhan ${ }^{a^{*}}$, Alexander Johnson ${ }^{\mathrm{a} *}$, Roshan Prizak ${ }^{\mathrm{a}, \mathrm{b}}$, Walter Anton Kaufmann ${ }^{\mathrm{a}}$, Barbara Casillas-Pérez ${ }^{\mathrm{a}}$ and Jiř́ Friml ${ }^{\mathrm{a}, 1, \S}$

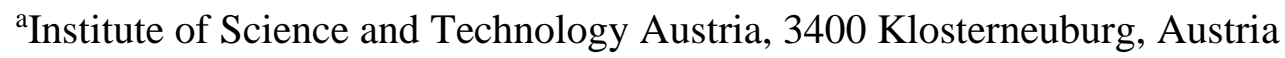

${ }^{\mathrm{b}}$ Institute of Toxicology and Genetics, Karlsruhe Institute of Technology, 76344

Eggenstein-Leopoldshafen, Germany

*These authors contributed equally

${ }^{1}$ Lead contact

${ }^{\S}$ Correspondence: jiri.friml@ist.ac.at

\section{SUMMARY (150 words)}

In plants, clathrin mediated endocytosis (CME) represents the major route for cargo internalisation from the cell surface. It has been assumed to operate in an evolutionary conserved manner as in yeast and animals. Here we report characterisation of ultrastructure, dynamics and mechanisms of plant CME as allowed by our advancement in electron microscopy and quantitative live imaging techniques. Arabidopsis CME follows the constant curvature model and the bona fide CME population generates vesicles of a predominantly hexagonal type; larger and with faster kinetics than in other models. Contrary to the existing paradigm, actin is dispensable for CME events at the surface but plays a unique role in collecting endocytic vesicles, sorting of internalised cargos and directional endosome movement that itself actively promote CME events. Internalized vesicles display a strongly delayed and sequential uncoating. These unique features highlight the independent evolution of the plant CME mechanism during the autonomous rise of multicellularity in eukaryotes. 


\section{INTRODUCTION}

Clathrin mediated endocytosis (CME) is the key cellular progress of internalising a cargo, either on the plasma membrane (PM) or outside the cell, into the cell. The cargos are packaged inside a small vesicle, which is covered by a coat made of the protein clathrin. CME represents a major endocytic route in eukaryotes (Goh et al., 2010). In plants, it is even more significant as most, if not all, endocytosis occurs via CME and many important PM proteins implicated in key physiological processes, such as growth and development, nutrient uptake or pathogen defence, are established cargos for the CME pathway (Barberon et al., 2011, Dhonukshe et al., 2007, Di Rubbo et al., 2013, Mbengue et al., 2016, Yoshinari et al., 2016). Therefore, CME in plants represents a major mechanism for regulating both local cellular signaling and the global response to external stimuli.

CME in plants is poorly characterized and its hypothesized mechanism is largely inferred from studies in mammalian and yeast systems, where CME components are highly conserved; with at least 60 homologous endocytosis accessory proteins (EAPs) well characterized in both these model systems (Merrifield and Kaksonen, 2014, Kaksonen and Roux, 2018, Lu et al., 2016, Taylor et al., 2011). Plants possess homologues of the many of the core EAPs, such as the clathrin coat proteins (e.g. CLC and CHC), adaptor proteins (e.g. all the AP2 subunits, AP180), dynamin like proteins (e.g. Drp1s and Drp2s) and uncoating factors such as Auxilin-like proteins (Chen et al., 2011, Baisa et al., 2013, Adamowski et al., 2018). However, functional characterisation of these, and other plant EAPs, is greatly lacking.

Despite a high degree of conservation between mammalian and yeast EAPs, there are key differences in the actual CME mechanism; chiefly related to the requirement of actin cytoskeleton. While actin co-localises with single sites of CME in both systems, interference with actin results in a total arrest of CME in yeast (Kaksonen et al., 2005) whereas in mammalian cells, there is only an overall reduction of endocytosis but still ongoing productive CME events (Taylor et al., 2012, Fujimoto et al., 2000, Merrifield et al., 2005, Yarar et al., 2005). This difference has been attributed to the higher turgor pressure of the cell wall-encapsulated yeast cells (Aghamohammadzadeh and Ayscough, 2009, Boulant et al., 2011, Dmitrieff and Nedelec, 2015). As plant cells are subject to equal or even higher turgor pressures compared to yeast cells (Beauzamy et al., 2014, Schaber et al., 2010), actin has been 
hypothesized to be crucial for plant CME; nonetheless, it has not been assessed in great detail.

Thus, despite the crucial physiological and developmental importance of CME in plants, little is known about its actual mechanism and how it differs from the wellcharacterized CME models in mammalian and yeast systems. One of the major reasons for this is the inability to directly observe CME and clathrin coated vesicles (CCVs) in vivo. For example, electron microscopy, the key technology credited for the first CME characterisation (Roth and Porter, 1964, Schmid et al., 2014), can be performed with plant tissues (Robinson, 1996, van der Valk and Fowke, 2011) but the successful capturing of ongoing CME events is rare. It is only recently that the plant field has started to adopt live imaging methods to directly look at the dynamics of CME events; like total internal reflective microscopy (TIRF-M) (Johnson and Vert, 2017, VizcayBarrena et al., 2011).

Here we provide a detailed characterisation of plant CME, starting with the formation of clathrin-coated pits (CCP) at the PM and up until the later endocytic events in the cell interior. We established new electron microscopy sample preparation protocols, which produced an abundance of clathrin-coated structures at an unprecedented level, and combined this with live quantitative TIRF-M imaging at a high spatial and temporal resolution. Contrary to expectations, actin is not present or required during $\mathrm{CCV}$ formation on the PM, but is critical for the early post-endocytic traffic supporting an unsuspected active role of dynamic actin and moving endosomes in organizing CME events at the PM. Imaging of CCVs deeper inside the cell revealed strongly delayed and gradual uncoating on route to the endosomes. Thus, we provide an extensive mechanistic framework for CME in plants and identify multiple unexpected, evolutionary non-conserved aspects of this fundamental cellular process. 


\section{RESULTS}

\section{Different populations of clathrin-coated structures at plasma membrane and endomembrane system}

Endocytic events have not yet been well characterized in planta, largely due to the lack of efficient ultra-structure analysis of the key events of CME. Therefore, we established a method for using Scanning Electron Microscopy (SEM) on metal replicas of unroofed Arabidopsis cells.

This technique provided a detailed view of well-preserved CCPs at various stages of invagination at the PM and fully formed CCVs deeper inside the cell often attached to cytoskeletal and endomembrane structures (Figure 1A and S1A, B). It allowed us for the first time to address the types of assemblies of clathrin polygons that together form the clathrin coat. By closely analyzing the surface view of the clathrin baskets at the PM, we categorized the clathrin coated structures (CCSs) into distinct populations based on the basket diameter and shape (Figure S1C). The first characterised population consists of a basket with a central polygonal ring surrounded by 6 other rings; the progression of this basket type formation could be seen at the PM (Figure 1B). The final spherical vesicle has a hexagonal en face surface view, hence was categorized as hexagonal basket type. The second population of CCSs consists of a basket with a pentagonal surface view with one central polygon surrounded by 5 others, hence a pentagonal basket type (Figure 1C, left). Both these types of CCSs are small with a basket diameter of $60 \mathrm{~nm}$ (15 cells, 190 CCSs measured). The third population consists of a more irregularly ordered basket with a larger diameter, ranging between 80-110 $\mathrm{nm}$ (15 cells, $72 \mathrm{CCSs}$ measured) (Figure 1C, right). At the endomembrane surface, we observed CCSs conforming to all typical basket types (Figure 1D and S1D). And the frequency distribution of the populations were similar in both the PM and the endomembrane structures, with the prominent type being hexagonal (60\%) (Figure 1E). Typically for endomembranes there were multiple CCSs fused together, the occasional occurrence of huge CCSs and also large aggregations of CCSs comprising of same or different population types (Figure 1F, S1E-G). These endomembrane structures have been previously reported to be the Early Endosome/Trans-Golgi Network (EE/TGN) or the poly-coated reticulum (Galway et al., 1993, Tanchak et al., 1988, Kang et al., 2011, Robinson, 2015). The CCSs at the endomembranes could be secretory vesicles budding off the TGN (Kural et al., 2012, 
Robinson and Pimpl, 2014, Watanabe et al., 2014, Kirchhausen, 2000) or if the uncoating in plants would be delayed, they can be also endocytosed CCVs fusing to the EE.

These observations show that metal replica of unroofed cells provide an unprecedented insight into various structural aspects of plant CME. It revealed the existence of distinct populations and arrangements clathrin structures at the PM and various endomembrane structures.

\section{Constant curvature mode of clathrin-coated pit formation at plasma membrane}

Next, we used the metal replicas to determine the mechanism of CCP formation in plants. The mechanism of membrane bending has been studied extensively in yeast and mammalian models (Kaksonen and Roux, 2018, Lampe et al., 2016, Sochacki and Taraska, 2019), where two major models have been proposed (Figure 1G). The 'constant area' model; where clathrin initially forms a flat lattice on the PM, and then through continuous exchange of clathrin molecules bend the membrane. Thus, during membrane bending, the radius of curvature continuously decreases, in effect modifying the en face view from a large flat lattice to a smaller curved dome (Figure $\mathrm{S} 1 \mathrm{H}$ ) (Avinoam et al., 2015). Moreover, in mammalian systems CCPs also mature and bud off the large clathrin-coated surfaces: plaques and flat clathrin lattices (Grove et al., 2014, Lampe et al., 2016, Leyton-Puig et al., 2017). The second model is the 'constant curvature' model. The clathrin assembly at the invagination directly bends the membrane and the continuous polymerization develops the curvature. Such a mode of development maintains the radius of curvature; hence the en face surface view of the pit stays the same (Figure S1H) (Kaksonen and Roux, 2018, Lampe et al., 2016, Bucher et al., 2018). We therefore used the SEM images of unroofed protoplasts to make a comprehensive surface view analysis of the clathrin at the PM, as all stages of CCP development were evident.

First, we found that there was an absence of large clathrin assemblies or lattices in Arabidopsis (Figure 1A and S1A). Most of the lattices that were found were small, with only a few clathrin polygons, consistent with early reports in other plant species (Emons, 1986, Coleman et al., 1988). We also observed the same hexagonal surface view in the developing pits until they reached a rounded matured stage; meaning the hexagonal pits projected a constant en face surface view along all stages (Figure 1B, $\mathrm{S} 1 \mathrm{H})$. This shows that the radius of curvature of the CCPs is pre-defined and maintained 


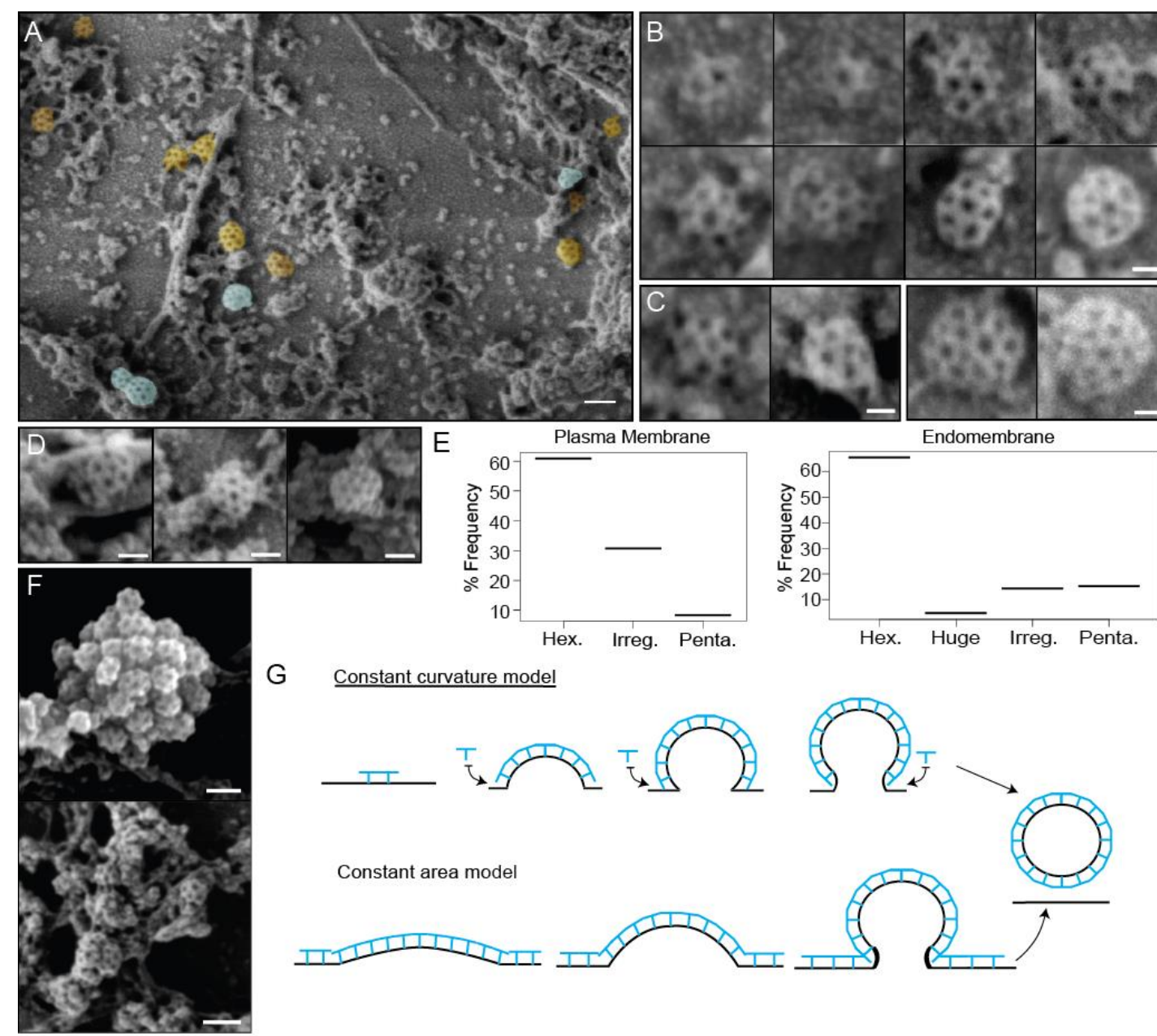

Figure 1: Ultrastructural characterization of clathrin-coated structures in unroofed protoplasts by SEM

A) SEM image showing CCSs found associated to the PM (orange) and endomembrane structures (blue). See also Figure S1A, B.

B) Representative images depicting the sequential (left to right) development of the hexagonal CCV.

C) Representative pentagonal CCSs (left) and irregular basket types (right) at the PM.

D) Representative images of isolated CCSs of pentagonal, hexagonal and irregular basket types at the endomembrane structures.

E) Example aggregated and partial fused CCSs at the endomembrane structures. See also Figure S1 E-G.

F) Histograms showing the different populations of CCSs at the PM (left) and endomembrane structures (right). 166 CCSs from the PM and 104 CCSs from the EM structures pooled from $\mathrm{N}=15$ cells). 
G) Two potential models of clathrin-mediated membrane bending. The constant curvature model suggests that as the membrane is bending inwards, clathrin is recruited to the invagination. The constant area model depicts that clathrin is already on the PM and the whole area bends the membrane inwards. See also Figure S1H. Scale bars; $100 \mathrm{~nm}$ (A, E upper panel), $30 \mathrm{~nm}$ (B, C), $50 \mathrm{~nm}$ (D) and $60 \mathrm{~nm}$ (E lower panel).

during CCP maturation, thus demonstrating that CCV formation in Arabidopsis follows 'constant curvature model' (Figure 1G).

To verify these observations independently, we used live imaging with TIRF$\mathrm{M}$, which excels at looking at cell surface processes due to its shallow illumination penetration depth of $\sim 100 \mathrm{~nm}$ (Axelrod, 2001). We directly observed the PMs of plants expressing CLC2-GFP and detected small foci rather than large plaques of fluorescence signal (Figure 2A). We also generated the intensity time course of the fluorescent signal obtained from clathrin tracks. The intensity profile show an initial steep increase of signal (representing the assembly of clathrin at the pit), followed by a plateau phase (representing the maturation phase of the CCP), and finally a sharp drop in intensity (corresponding to the scission and release of the CCV) (Figure 2B); which is reminiscent of the clathrin intensity profiles reported in mammalian cells (Loerke et al., 2009). The maturation phase accounts for only $17.8 \pm 8 \%$ of the entire span of development, while the assembly phase takes up to $42 \pm 5 \%$. Such a segregation in the intensity profile is consistent with the 'constant curvature', rather than 'constant area' model, which entails a short assembly and very long maturation phases (Avinoam et al., 2015).

In summary, ultrastructural and live imaging analysis of clathrin at the PM did not detect any larger clathrin lattices that could develop into vesicles. Moreover, the ultrastructure observations of CCP developmental stages and live imaging-based clathrin intensity profiles at the CCPs clearly shows that the predominant mode of the clathrin-mediated membrane bending in Arabidopsis follows the 'constant curvature' model. 


\section{Productive populations of clathrin-mediated endocytic events at cell surface}

While TIRF-M has been used in plants (Vizcay-Barrena et al., 2011, Johnson and Vert, 2017, Wan et al., 2011), a detailed analysis of the clathrin kinetics and characterization of endocytic events at the cell surface has not yet been performed. With improvements of imaging protocols, automated particle detection and tracking analysis is now feasible (Johnson and Vert, 2017, Wang et al., 2015). We therefore combined TIRF-M with automated particle detection and tracking analysis to characterize in detail the CME kinetics on the cell surface.

A large data set of lifetimes was generated (12 cells and 149162 tracks) by imaging plants expressing CLC2-GFP. Notably, the mean lifetime of all the clathrin tracks was $23.14 \mathrm{~s}$, which closely matches the lifetime reported based on manual measurements (Konopka et al., 2008). The histogram of this data set appears to be exponential (Figure 2B), suggesting that the majority of clathrin imaged were in fact transient events. Therefore, to further characterize the kinetic behavior of clathrin, and uncover the lifetime of the bone fide clathrin endocytic population, we used an approach based on a mixture model distribution fitting (Loerke et al., 2009). Further statistical testing of the experimental data revealed that 3 populations produced the best fit (Figure S2). There were 2 short-lived sub-populations identified with lifetimes of $1.79 \mathrm{~s}$ (accounting for $6.31 \%$ of the total population) and $8.92 \mathrm{~s}$ (accounting for $50.6 \%$ of the total population). The third population accounts for $43.9 \%$ of all clathrin on the surface and had a lifetime of $42.01 \mathrm{~s}$ (Figure 2C).

To confirm if this longer-lived sub-population represents bona fide CME, we used dual channel TIRF-M on root cells expressing CLC2-GFP and an additional endocytosis marker TPLATE, which has been proposed to function as an endocytic adaptor (Gadeyne et al., 2014). One would expect bona fide CME events to be positive for both markers and indeed, the mean lifetime of the tracks positive for both markers was $42.02 \mathrm{~s}$ (Figure 2C, D, E). We also conducted clathrin departure assays on these dual channel experiments. Briefly, the end of the clathrin track depicts when it has left the illumination area of the TIRF evanescent wave, thus representing when the vesicle has been scissioned from the membrane (Johnson and Vert, 2017, Mattheyses et al., 2011, Merrifield et al., 2002). Tracks with the mean lifetime were combined to generate a mean fluorescent intensity profile of both channels relative to the departure of clathrin. TPLATE shows concurrent recruitment to the site of endocytosis, and clathrin shows a profile which fits the expected intensity profile of CME event; where it 

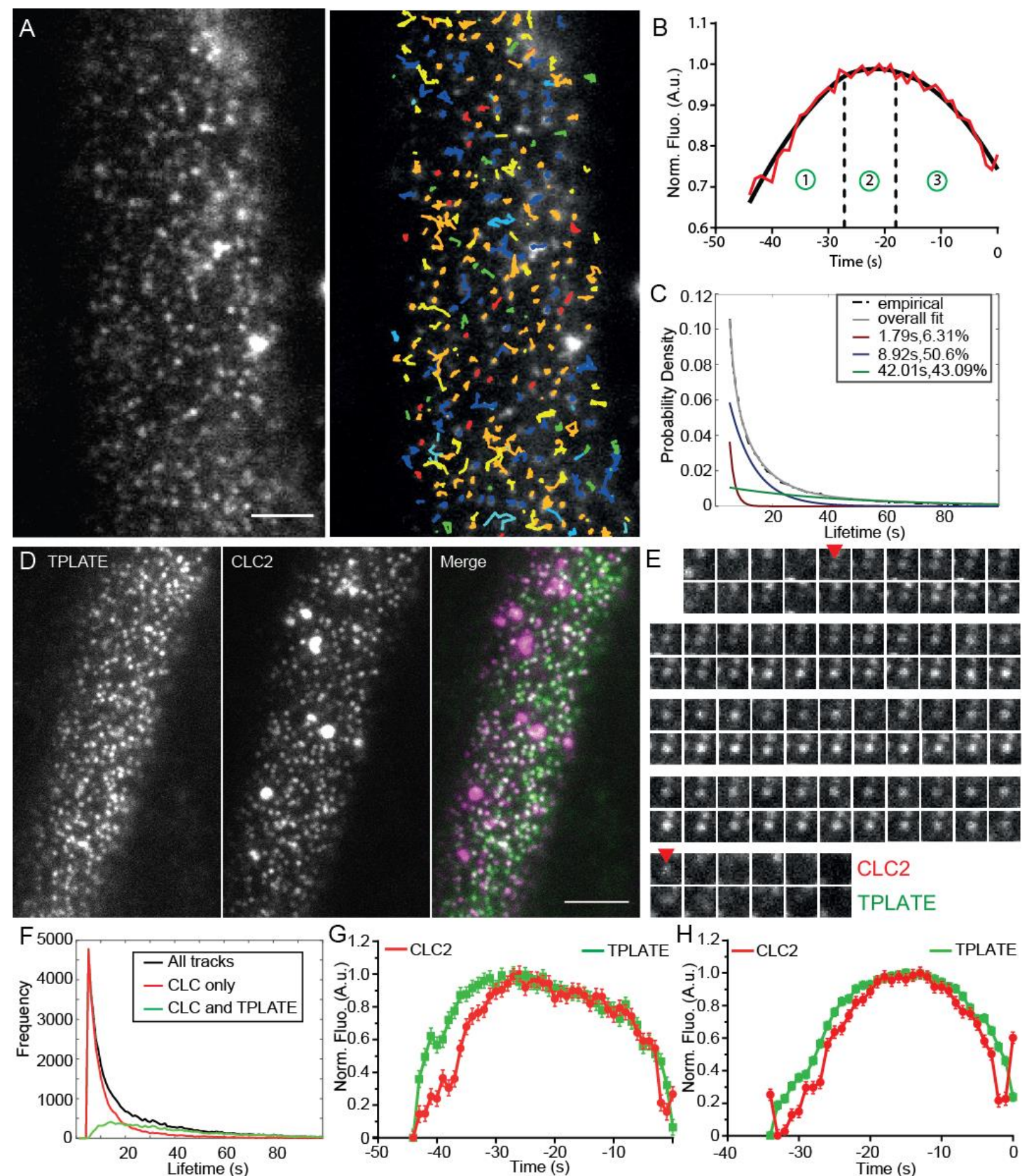

Figure 2: Characterization of clathrin kinetics at the cell surface

A) TIRF-M image of clathrin foci in the root epidermal cell expressing CLC2-GFP (left) and the automated tracking results (right).

B) Intensity-time course of the combined mean fluorescence profile (along with a smoothening curve) of CLC2-GFP in root epidermal cells. The intensity profile depicts different CCP developmental phases; (1) assembly, (2) maturation and (3) scission. The points represent mean \pm SEM of the mean intensity of all the trajectories that have the mean lifetimes. $\mathrm{N}=5$ cells from individual roots, 182 trajectories.

C) Normalized histogram of CLC2-GFP tracks (black) with 3 exponential distributions fitted (red, blue and green). The inset denotes the mean lifetime and the percentage 
contribution to the total population of each sub population. $\mathrm{N}=12$ cells from individual roots, 149162 tracks. Also see Figure S2.

D) Dual channel TIRF-M image of root epidermal cell expressing TPLATE-GFP and CLC2-RFP.

E) Time series of an isolated endocytic event positive for CLC2-RFP and TPLATEGFP. Arrows mark the appearance and the disappearance of CLC2.

F) Frequency distribution of the lifetimes of clathrin and TPLATE tracks. The inset indicates the color codes marking the frequency distributions of different sets of tracks. G) Clathrin departure assay of TPLATE-GFP and CLC-tagRFP in root epidermal cells. $\mathrm{N}=6$ cells from individual roots, 16756 tracks.

H) Clathrin departure assay of TPLATE-GFP and CLC-tagRFP in hypocotyl. $\mathrm{N}=3$ cells from individual hypocotyls, 1460 tracks.

Scale bars; $10 \mu \mathrm{m}$ (A and D).

gradually assembles as the invagination grows (assembly phase), plateau (maturation phase) and then decreases upon scission and release (Figure 2G). Additionally, the lifetime of CLC2 when colocalized with another adaptor AP2 (Di Rubbo et al., 2013) confirmed these observations, as its lifetime was found to be similar, 43.49 s. Thus, the empirically obtained bona fide population of endocytic events matches the mathematically simulated longer-lived sub-population collectively suggesting the lifetime of CME events in root to be about $42 \mathrm{~s}$.

Use of the intact plants allowed us to compare the kinetics of CME in different organs. The same analysis of CLC2 and TPLATE positive tracks in Arabidopsis hypocotyls produced a significantly shorter mean lifetime of $33 \mathrm{~s}$ (Figure 2H).

Thus, the mathematical analysis of CLC2 lifetime histograms and dual channel TIRF-M imaging independently reveal a lifetime of about 42 and $33 \mathrm{~s}$ for the bona fide CME events in root and shoot cells, respectively and suggested a so far unappreciated organ-specific regulation of CME in plants.

\section{Absence of actin accumulation at the endocytic foci}

Clathrin pit invagination requires the use of accessory proteins to provide force, in order to overcome the energetic cost of physically altering the membrane structure against the resistive forces of the cell. In yeast, and in mammalian cells with high membrane 
tension, actin is considered the major force generator aiding membrane invagination (Kaksonen and Roux, 2018, Kaksonen et al., 2005, Saleem et al., 2015, Stachowiak et al., 2013). Actin polymerizes around the endocytic pit and with pushing and pulling actions, it aids the invagination to form against the tension and turgor pressure (Picco et al., 2015, Toshima et al., 2006, Brady et al., 2010, Buser and Drubin, 2013). Plant cells, similar to yeast are enclosed within a cell wall and possess high turgor pressure values 0.3 - $1 \mathrm{MPa}$ (Cosgrove, 1993); therefore actin has been assumed to play a key role in membrane invagination during plant endocytosis (Robatzek et al., 2006, Chen et al., 2011).

Using SEM on unroofed protoplasts, we were able to observe the arrangement of cortical actin. Deeper inside the cell, actin exhibits a more complicated network (Figure S3A) but closer to the PM, we observed only thick main filaments and several thinner subsidiary filaments but, unexpectedly, never an enrichment of actin around the CCPs (Figure 3A).

In complementary experiments using TIRF-M on Actin-Binding Domain 2GFP (ABD2-GFP) transgenic plants, we were able to analyze intact cortical actin filaments in hypocotyl epidermal (Figure 3B). They formed a filamentous network of cortical actin consisting of thick main filament and numerous branches of dynamic subsidiary filaments, as previously reported (Staiger et al., 2009). In accordance with our SEM analysis of the protoplast replicas, we observed no actin concentrations at the PM. In addition, in root hair cells, when we assessed the localization of actin and the localizations of CCPs at the PM (marked by Dynamin-Related Protein (Drp1C)), actin did not concentrate foci on the PM, unlike the CCP markers (Figure 3C). Examination of additional actin markers (Lifeact, ABD2 and mTalin) also failed to reveal accumulations of actin around sites of CME (Figure S3B).

Thus, in contrast to expectations based on observations in yeast and some mammalian systems, where CCP invagination is facilitated by actin polymerization, plant cortical actin only forms filaments and does not accumulate around the invaginating CCPs as concrete foci.

\section{Actin is not mandatory during CCP formation and cargo internalization}

The absence of actin foci at the endocytic spots is unexpected given that actin polymerization energy had been proposed to be a critical factor for plant CCP development. 
In order to test the importance of actin in $\mathrm{CCV}$ formation, we perturbed actin by either stabilization of actin filaments treating with Jasplakinolide (Jasp) or depolymerisation (Figure S3C) treating with LatrunculinB (LatB). Using TIRF-M, we directly visualized the dynamics of the endocytic events at the PM using different endocytic markers; TPLATE, CLC2 and DRP1C. After prolonged treatment with $5 \mu \mathrm{M}$ Jasp, which lead to extreme structural abnormalities of the actin filaments, CCVs marked by CLC2-mKO formed and were removed from the PM with no apparent arrest of pits (Movie S1). Moreover, we observed no clear changes in the overall lifetime distribution and foci density of any of these EAPs after $10 \mu \mathrm{M}$ LatB and $5 \mu \mathrm{M}$ Jasp treatments in both hypocotyl and root cells (Figure 3D and Supplementary table 1).

We also examined whether actin perturbations cause disturbances in CCP development, such as delays in assembly and/or maturation. We observed the intensity profile of bona fide endocytic sub-population of CCPs with the lifetime of $44 \mathrm{~s}$ (Figure $3 \mathrm{E})$ and sub-populations with lifetime of $22 \mathrm{~s}$, the overall mean of the total population (Figure S3D). Again, we saw no significant changes in the average duration of any of the developmental phases: CCP initiation, maturation or scission, after LatB treatment. All these results show that depolymerizing or stabilizing actin has no effect on CCP development and the rate of endocytosis.

Next, we tested the importance of intact actin on CCP productivity by observing the internalization of different endocytic cargoes. We used the endocytic tracer, the dye FM4-64 (Jelinkova et al., 2010) in root cells and observed that after LatB and Jasp treatments, PM internalization still occurred (Figure 3F; S3E), consistent with observations in a more primitive plant Chara (Klima and Foissner, 2008). We also tested the effect of actin perturbation on receptor-mediated endocytosis in hypocotyls by following flagellin (flg22)-mediated internalization of its receptor FLS2. After flg22 application, FLS2 is endocytosed and can be visualized in ARA7-labeled endosomes after 40 min (Beck et al., 2012). Again, following LatB treatment, FLS2 endocytosis still occurred and the receptors reached the endosomes as expected (Figure 3G). Next, we directly measured the rate of internalization of PIN2; a PM-localized auxin transporter in root epidermal cells, which undergoes constitutive endocytosis and recycling to the PM (Adamowski and Friml, 2015). PIN2 was tagged with photoconvertible Dendra and the existing PIN2 population in the root was photo-converted to red leaving the de novo synthesized population green. The loss of photo-converted red PIN2 PM signal was monitored over time, which denotes the rate of its endocytosis. 

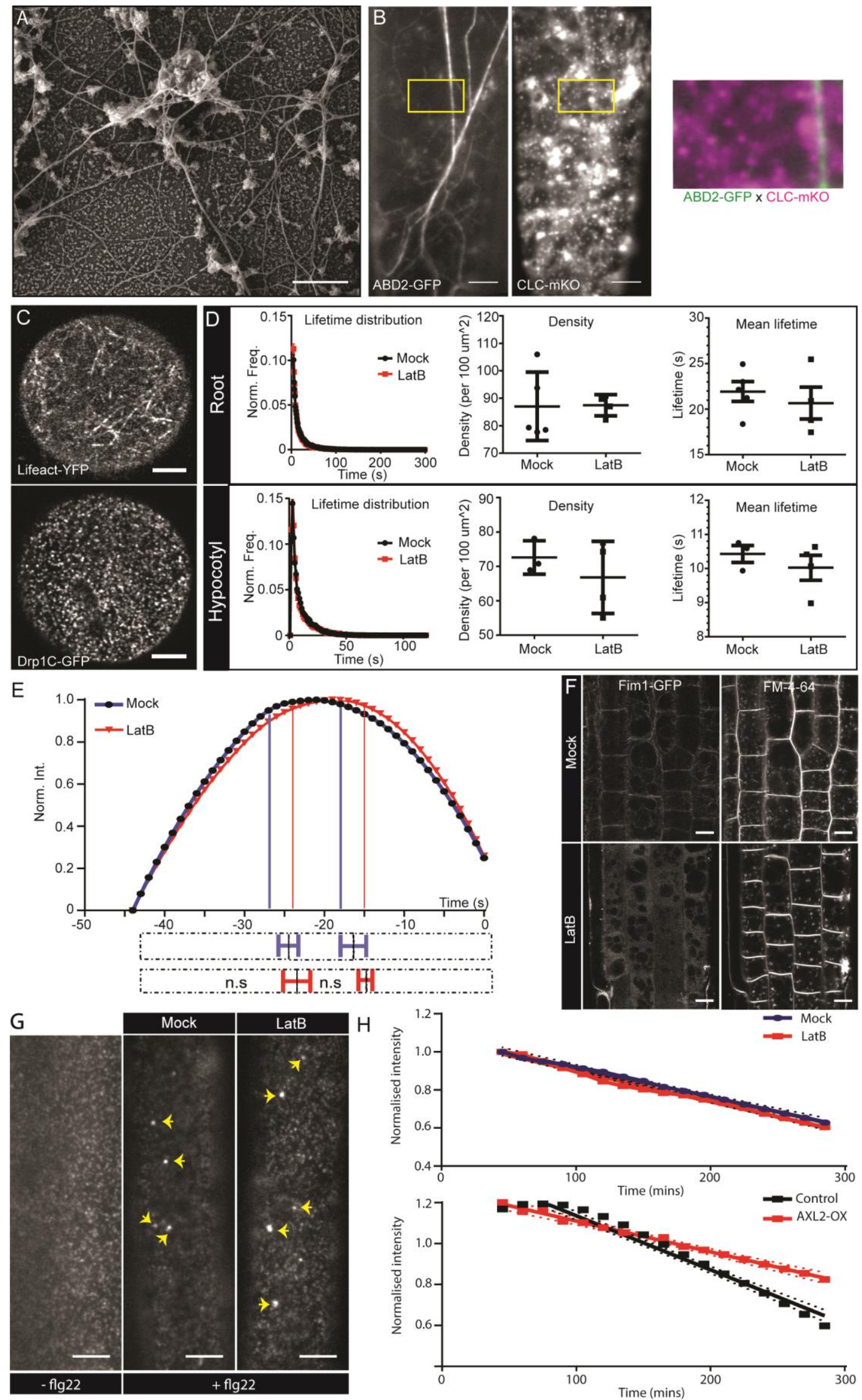

Figure 3: Localization and functional importance of actin during endocytosis 
A) SEM image of the unroofed protoplasts showing the main and subsidiary filaments of actin in close proximity to the PM.

B) Dual channel TIRF image of hypocotyl epidermal cell expressing ABD2-GFP and CLC-mKO. The insert (yellow box) shows a magnified merge of the channels. Also see Figure S3B.

C) Example confocal airy-scan images of root hair cell expressing Lifeact-YFP (left) and the root hair cell expressing DRP1C-GFP (right).

D) Normalized lifetime distributions, average lifetime and densities of CLC2-GFP of root (upper panel) and hypocotyl (lower panel) epidermal cells in the absence (black) or presence (red) of LatB (roots; $10 \mu \mathrm{M}, 10$ mins, hypocotyl; $10 \mu \mathrm{M}, 1$ hour), measured by TIRF-M. Root: mock, 5 cells from individual roots, (32991 tracks), LatB, 4 cells from individual roots, (25517 tracks). Hypocotyl: mock, 3 cells from individual hypocotyls, (10883 tracks), LatB, 4 cells from individual hypocotyls, (12623 tracks). Error bars represent mean \pm SEM. Two-sided unpaired $T$ tests found there were no significant differences (Average lifetimes: hypocotyl $p=0.43$; root $p=0.53$. Average density: hypocotyl $\mathrm{p}=0.42$; root $\mathrm{p}=0.95$ ). (See also Supplementary table 1 for other markers).

E) Smoothened CCP intensity profile of the mean long-lived CLC2-GFP population in root epidermal cells in the absence (black) or presence (red) of LatB (10 $\mu \mathrm{M}, 10$ mins). Mock, 6 cells from individual roots, 182 trajectories, LatB, 4 cells from individual roots, 122 trajectories. The extrapolation lines mark the different CCP development phases. The bottom bar plot represents the phase transitions computed individually from the trajectories of each root. The dotted bars represent the whole time course of CCP development; the solid lines with error bars mark the mean \pm SD of the transition point between phases. Note that there are no significant differences in the different phases in the presence of LatB. One-sided Mann-Whitney U test; assembly $p=0.31$, maturation $\mathrm{p}=0.48$ (also see Figure S3D).

F) Confocal microscopy images of root epidermis expressing Fim1-GFP after mock of LatB treatment ( $20 \mu \mathrm{M}, 30$ mins). Actin cytoskeleton is disrupted but FM4-64 is still endocytosed. $\mathrm{N}=2$; at least 10 seedlings per condition.

G) TIRF-M images of the hypocotyl epidermal cells expressing FLS2-GFP either with or without flg22 (10 $\mu \mathrm{M}, 0.5$ hour) treatment, and also cells pretreated with 1 hour of mock or LatB (10 $\mu \mathrm{M}, 1$ hour) with co-treatment of flg22. Yellow arrows highlight endosomal structures containing FLS2. N=2, with 9 hypocotyls per condition. 
H) PIN2-Dendra endocytic rate, determined by the change of PM PIN2 intensity over time, after LatB (10 $\mu \mathrm{M}, 45$ mins) compared to mock treatment (top). The dots represent the mean intensity and the dotted lines represent the $95 \%$ CI. No significant difference is observed between the slope of the curves; LMER - random effects for position; $\chi^{2}-2.5923 ; \mathrm{df}=1 ; \mathrm{p}=0.107 ; \mathrm{N}=2,5$ seedlings per condition. (Bottom) PIN2Dendra endocytic rate with the mock induction conditions or induction of AXL2 overexpression (AXL2-OX) for 24 hours (bottom). The slope of the curve for AXL2-OX is significantly lower than control conditions; LMER - random effects for position; $\chi^{2}$ $=78.095 ; \mathrm{df}=1 ; \mathrm{p}<2.2 \mathrm{e}-16 * * * ; \mathrm{N}=2$, 4 seedlings per condition; all the epidermal cells in the root meristem were considered.

Scale bars; $0.5 \mu \mathrm{m}$ (A), $5 \mu \mathrm{m}(\mathrm{B}, \mathrm{G}), 4 \mu \mathrm{m}(\mathrm{C}), 10 \mu \mathrm{m}(\mathrm{F})$.

To validate this assay, we examined the PIN2-Dendra endocytic rate by overexpressing AUXILIN-LIKE2, which has been shown to inhibit CME (Adamowski et al., 2018), and found that the PIN2 endocytic rate was reduced (Figure 3H). In contrast, LatB treatment led to no significant change in the PIN2 endocytic uptake (Figure $3 \mathrm{H}$ ). These results show that the intact actin is not required for CME of multiple cargoes.

In conclusion, these multiple quantitative observations show that acute as well as chronic perturbations of the actin network do not have a major impact on CCP formation, CME dynamics or CME of multiple cargos in both Arabidopsis roots and hypocotyls.

\section{The role of actin role in EE/TGN dynamics and efficient endocytic trafficking}

Next, we investigated a possible role of actin in post-endocytic events, such as vesicular trafficking and EE formation. In contrast to mammalian cells, which typically utilize microtubules for subcellular organelle trafficking, in plant cells, it depends on actin filaments (Breuer et al., 2017, Geldner et al., 2001, Granger et al., 2014).

Each cell has several Golgi apparatus (GA) fused with EE/TGN compartments; which is specific to plant systems (Kang et al., 2011, Viotti et al., 2010). The EE/TGN compartments continuously form at, mature and detach from the trans-side of the GA (Kang et al., 2011) and dynamically move along actin filaments (Movie S2). Following depolymerizing or stabilizing the actin filaments, we observed a complete halt in the 
dynamics of the GA and the EE/TGN, which resulted in local aggregations of EE/TGNs (Figure 4A and 4B; Movie S3).

Despite this loss of dynamics, and the resulting aggregations, we observed that FM464 was still able to reach the agglomerated EE/TGN (Figure 4C). Nonetheless, we observed pronounced defects in the post-endocytic trafficking of cargoes such as PIN2. PIN2-GFP, which is normally observed at late endosomes marked by ARA7, was strongly mislocalized after prolonged actin perturbation. This was manifested by abnormally high amount of PIN2 in the aggregated late endosomal structures (Figure 4D). These trafficking defects are in agreement with our previous observation where interference of actin affected the arrival of PIN2 to the vacuole (Kleine-Vehn et al., 2008). This suggests that actin is required for the GA and EE/TGN dynamics and for the overall efficiency of post-endocytic trafficking processes.

\section{Actin-mediated early endosome dynamics for collecting and guiding CCVs}

Next, we examined the actin dynamics in relation to the endocytic events at the PM in detail. Using TIRF-M, we observed the dynamics of actin subsidiary filaments (marked by ABD2-GFP) and the CCVs (marked by CLC2-mKO). We observed a spatial and temporal correlation between the appearance of a small branch of an actin subsidiary filament and the disappearance of CCVs from the PM (Movie S4). This could possibly mean that the CCVs, after the scission and release, get whipped away by actin subsidiary filaments to get them moving along the network of actin. This live dynamic interaction is further supported by evidence from replicas of protoplasts where fully formed CCVs were observed attached along actin filament in close proximity to endomembrane structures (Figure 5A).

To gain a further insight into the possible role of actin in organizing the early post-endocytic traffic, we followed the actin-mediated dynamics of the GA and the EE/TGN along with the CCVs. The EE/TGN moves typically synchronously with GA, loosely associated with it (Kang et al., 2011). While studying movement of these structures, we observed that on their way below the PM, they pick up/collect the scissioned CCVs (Figure 5B; Movie S5 and 6). To provide an unbiased verification of this phenomenon, we developed an automated 'endosomal pick-up' analysis in root and hypocotyl cells. This provided a percentage of productive CCV tracks (identified by being positive for both CLC and TPLATE) that ended in the 'endosomal' regions of interest (ROIs) corresponding to $\mathrm{CCV}$ s being scissioned while the endosome was 

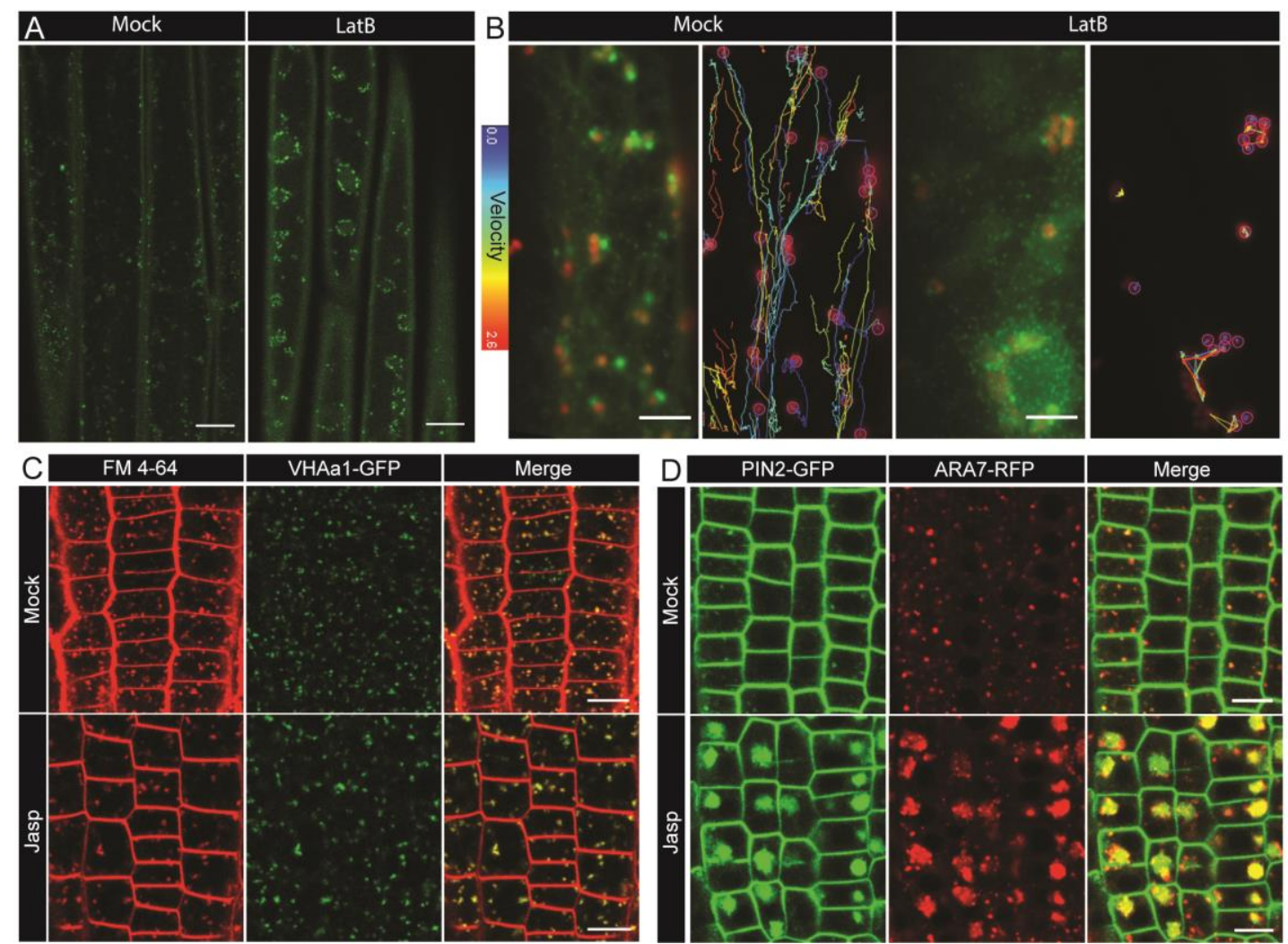

Figure 4: Role of actin in post-endocytic trafficking

A) Confocal microcopy images of EE/TGN (marked by CLC2-GFP) aggregated after mock or LatB (10 $\mu \mathrm{M}, 1$ hour) treatment in hypocotyl epidermal cells. $\mathrm{N}=5$ hypocotyls per condition.

B) TIRF-M images of Golgi (ST-RFP) and EE/TGN (CLC2-GFP) structures (left panel; see also the Movie S3) and the velocity profile by tracking the Golgi (right) after mock and LatB $(10 \mu \mathrm{M} ; 1 \mathrm{~h})$ treatment. $\mathrm{N} \geq 15$ cells per condition. The tracks are very short and belong to low velocity profile after LatB.

C) Confocal microcopy images of the root epidermis expressing VHA-a1-GFP with either mock or Jasp treatment ( $5 \mu \mathrm{M}, 30$ mins). $\mathrm{N}=7$ roots per condition.

D) Confocal microcopy images of the root epidermis expressing PIN2-GFP and ARA7-RFP (marking LE) after mock of Jasp ( $5 \mu \mathrm{M}, 5.5$ hours). $\mathrm{N}=8$ roots per condition.

Scale bars; $15 \mu \mathrm{m}$ (A), $5 \mu \mathrm{m}$ (B), $10 \mu \mathrm{m}$ (C, D). 
passing close by (Movie S7). We found that there was a significant increase in the percentage of CCV tracks ending in the 'endosomal' ROIs compared to 'control' ROIs (Figure 5C) providing unbiased and quantitative evidence that actin-organized movement of EEs aids collecting the CCVs after their scission.

All these observations together with the in vivo imaging of endocytotic events at the PM suggest that actin filaments traffic the CCVs directly from the site of endocytosis. Also, actin guides the EE/TGN compartments movement to "collect" CCVs as they move. This is not only a first observation how EE in plants are formed by directional traffic and fusion of $\mathrm{CCVs}$, but it also suggests a more active role of endocytic compartments in organizing the early post-endocytic events (Furthauer and Gonzalez-Gaitan, 2009, Gonzalez-Gaitan, 2003, Platta and Stenmark, 2011).

\section{Delayed and sequential uncoating of scissioned clathrin-coated vesicles}

Many well established models of CME assume that CCVs shed their coat rapidly after the scission event, in order to be able to fuse with EE (Beck et al., 1992, Massol et al., 2006, Sekiya-Kawasaki et al., 2003, Bocking et al., 2011). The key mammalian uncoating proteins, auxilins and Heat shock cognate $71 \mathrm{kDa}$ protein (HSC70) proteins, have been shown to be crucial for efficient endocytosis (Bai et al., 2010, Greener et al., 2000, Lee et al., 2008, Yim et al., 2010, Hirst et al., 2008). While auxilins appear to be conserved in plants, they are not essential for endocytosis or development (Adamowski et al., 2018), implying that uncoating in plants may work differently.

While closely following the CCVs and the EEs with TIRF-M, we noticed that while some CCVs lose their clathrin coat (Movie S8), many others retained their coat all the way till they reached the EE/TGN compartment (Figure 5A, Movies S5 and S6). This implies that the clathrin coat does not get disassembled immediately after scission, unlike in animal cells.

Following this unexpected observation, we analyzed the mechanism of uncoating in further detail. We closely observed the clathrin-coat disassembly by following two components of CCVs; CLC2 and TPLATE. While tracking CCVs leaving the PM, we observed CCVs that immediately fuse into the EE and CCVs that are present in the cytosol for a longer time period. For the CCVs immediately fusing with EEs, both clathrin and TPLATE were retained until the vesicles reached the EE. However, after fusion, the EE compartment did not contain any visible TPLATE, implying that the uncoating process had taken place, at least partially, but immediately 
A ST-RFP $\mathbf{x}$ CLC2-GFP
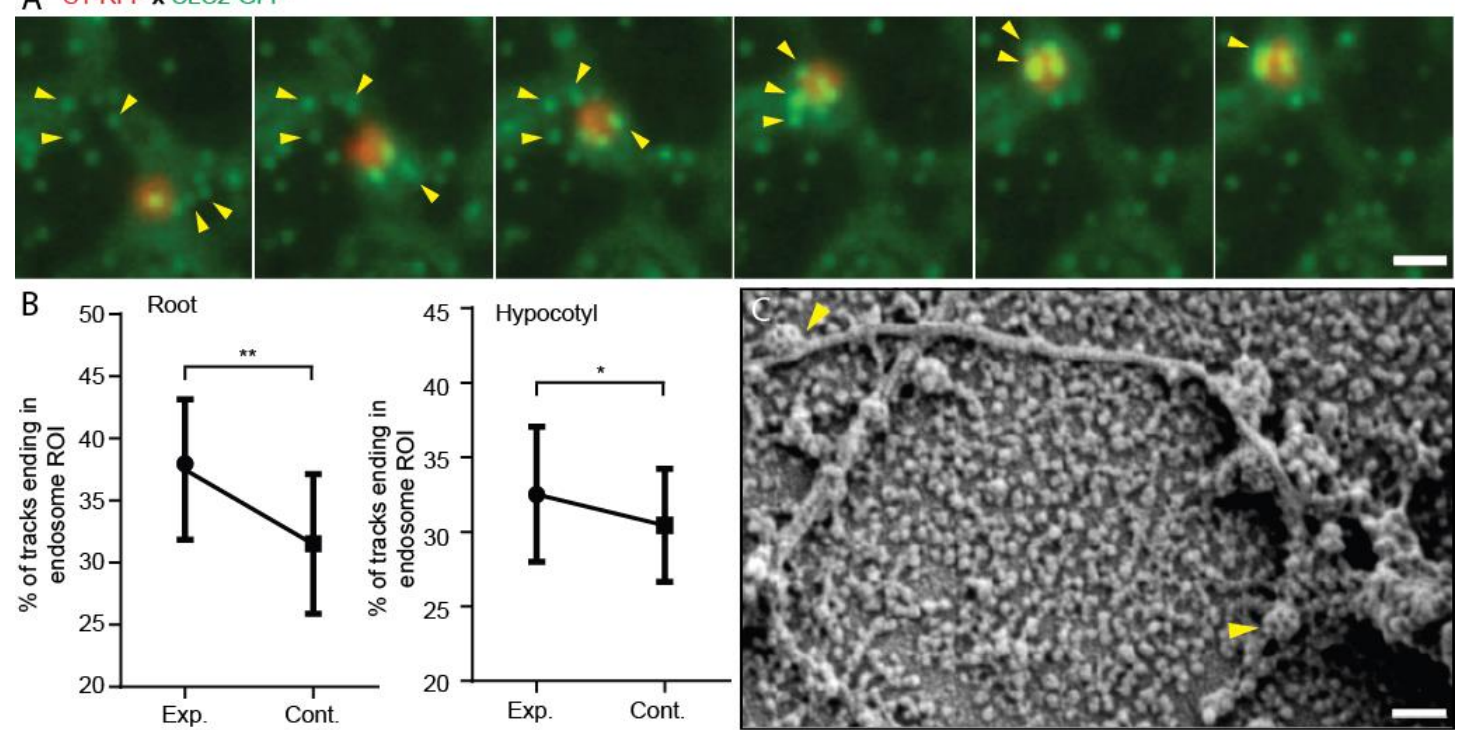

Figure 5: Role of actin and early endosome movement in CME

A) TIRF-M images of hypocotyl epidermal cells expressing ST-RFP and CLC2-GFP.

The Golgi apparatus (marked by ST-RFP) which move towards the endocytosed

CCVs (marked by CLC2-GFP) are marked by arrows. Time interval: $1.9 \mathrm{~s}$. See also Movie S5.

B) Endosomal pick-up analysis of CCVs positive for both CLC2-tagRFP and TPLATE-GFP in root (left) and hypocotyl (right) cells. Higher proportion of CME events terminates when EE passes by below the PM. $\mathrm{N}=6$ root cells and 622 endosome tracks, 6 hypocotyl cells and 1539 endosome tracks. The plot represents the mean \pm SD. Paired two-sided t test $\mathrm{p}=0.0066 * *$ for root and $\mathrm{p}=0.0223 *$ for hypocotyl.

C) SEM image of unroofed protoplasts, where arrows depict CCVs attached to an cytoskeleton filament.

Scale bars, $1 \mu \mathrm{m}(\mathrm{A}), 100 \mathrm{~nm}(\mathrm{C})$.

before or during the fusion (Figure 6A; Movie S9). This hypothesis is supported also by ultrastructural analysis, where aggregates of partially coated CCVs fused to the endomembrane structures were detected (Figure 1E). This also supports that some $\mathrm{CCV}$ s remain partially uncoated at the EE.

For the CCVs being trafficked for a longer duration in the cytosol before reaching the EE, we were often able to observe the loss of TPLATE before clathrin (Figure 6B; Movie S10). This means that the disassembly of the released CCVs does not typically happen all at once but sequentially. The sequential loss of coat was observed in the majority of cases $(18 / 20 \mathrm{CCVs})$; whereas in the remaining traced CCVs 

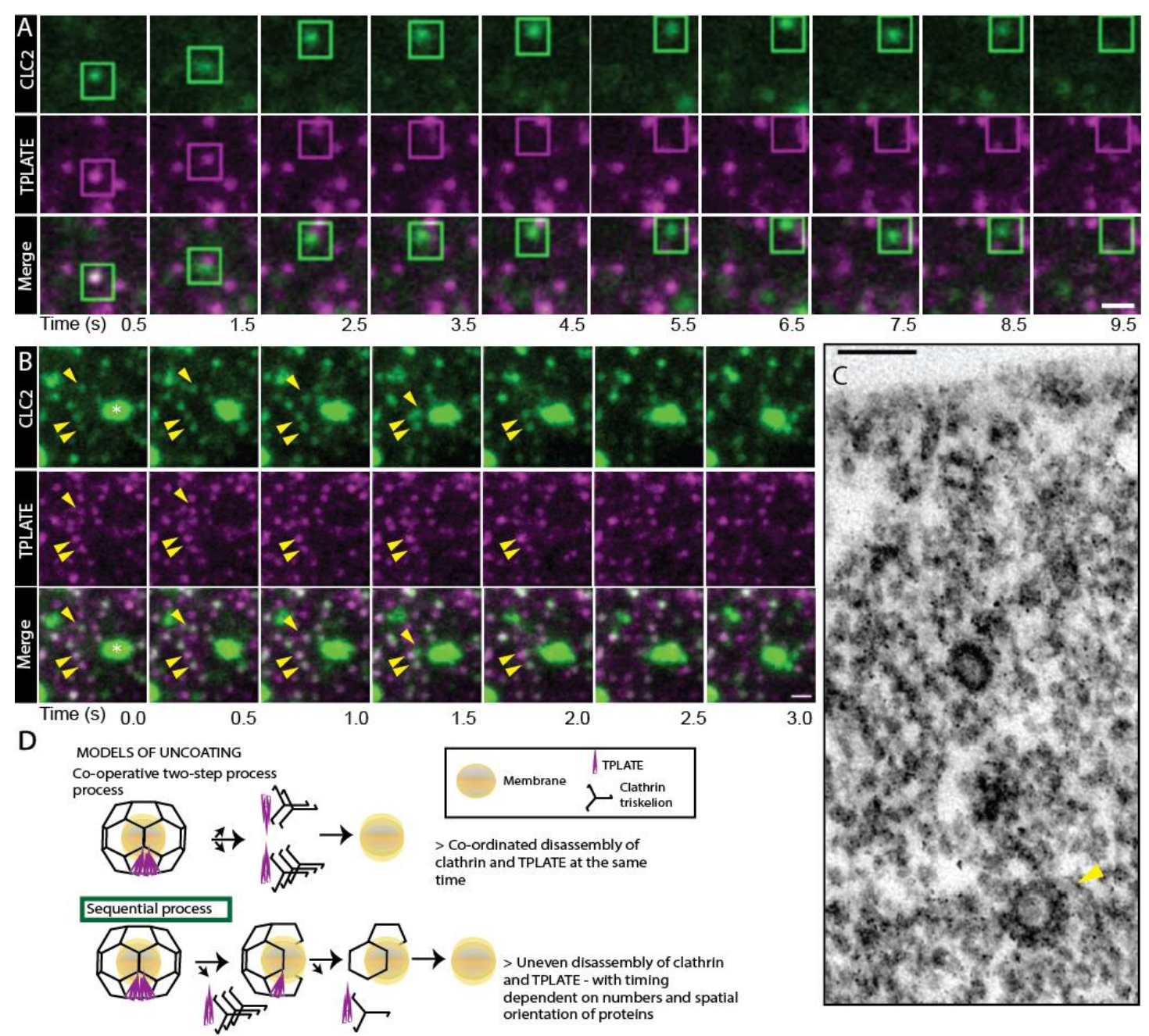

Figure 6: Uncoating of CCVs

A) and B) TIRF-M images of hypocotyl epidermal cells expressing TPLATE-GFP and CLC2-tagRFP. CLC2 marks both endocytic foci (smaller foci) and the EE/TGN (larger structures). A) The boxed CCV is followed after internalization into cytosol.

Time interval: $1 \mathrm{~s}$. See also Movie S8. N = 19 events pooled from 5 cells

B) CCVs indicated by arrows reach the stationary EE/TGN while still containing clathrin (white asterisk). Time interval: $0.5 \mathrm{~s}$. See also Movie S9.

C) TEM image of a resin embedded and ultra-thin sectioned protoplast. The yellow arrow denotes a CCV with partially removed coat deeper in the cytosol.

D) Models of clathrin coat removal. (top) Co-operative disassembly, where the disassembly of clathrin and TPLATE is temporally coordinated. (bottom) Sequential disassembly, where TPLATE, is able to disappear before clathrin.

Scale bars, $1 \mu \mathrm{m}$ (A, B), $100 \mathrm{~nm}(\mathrm{C})$. 
both components vanished together. This sequential uncoating is also supported by TEM observations, in which we can detect partially uncoated CCVs deeper in the cytosol (Figure 6C).

In summary, multiple independent observations show that in plants uncoating of the CCVs does not happen immediately (co-operative process) after scission at the endocytic spot, but the clathrin coat is retained for a prolonged time, shedding its components gradually (sequential process) on its way to the EE (Figure 6D). 


\section{DISCUSSION}

Endocytosis is a crucial cellular process in all eukaryotes regulating a multitude of fundamental cellular functions. In plants, CME has emerged as the major, if not the exclusive (Dhonukshe et al., 2007), mode of endocytosis crucial for number of developmental and physiological processes. Nonetheless, a precise characterization of plant CME is greatly lacking when compared to other model systems. By developing and advancing imaging methods, we were able to provide a detailed characterisation of plant CME in Arabidopsis tissues. We found that while there is some evolutionary conservation of endocytic molecular components between plants and other model systems (Baisa et al., 2013, Chen et al., 2011), mechanism of plant CME and postendocytic processes shows multitude of unique features compared to other model systems.

\section{Key characteristics of plant $\mathrm{CME}$}

A major reason for the lack of plant CME characterization is poor implementation of techniques to directly examine CCVs and live CME events in plant cells. Here, by combining advanced SEM and TEM, advanced live imaging and automated, quantitative analysis techniques, we provide the detailed visualization of every stages of the CCV formation and trafficking away from the PM to the EEs, at unprecedent resolutions.

We determined the typical Arabidopsis CCVs possess a hexagonal clathrin cage, with an average diameter of $60 \mathrm{~nm}$. They locate on the PM, on actin filaments and at aggregations at the EEs/TGNs. Combining direct ultra-structural analysis of CCPs with high temporal resolution live imaging of CLC2 allowed us to determine that Arabidopsis CCP formation follows the 'constant curvature model'. This is supported by the lack of large clathrin lattices discovered on the PM, which in mammalian systems represent hubs of CME (Leyton-Puig et al., 2017).

The large-scale examination of live Arabidopsis revealed the existence of 3 kinetically distinct populations of CLC2 on the root PM. While the majority of the events were in fact transient and likely non-functional, the bona fide CME population had a mean lifetime of 42 seconds and accounted for $44 \%$ of the total CME events at the PM. The discovery of differences in the bona fide lifetime between tissues suggest that there are organ- and tissue-specific modulations of CME in plants. 
Compared to yeast models (Lu et al., 2016), the plant CME appears to be much faster and the resulting endocytic vesicles are almost twice the size. This suggests that plants have differential regulatory processing of recycling clathrin compared to animals and yeast.

\section{Actin-independent mechanism of plant CME}

Actin has been emphasized to be important for CME in mammals and crucial in yeast, where it is required for detaching the PM from the cell wall, and for deforming the membrane locally against the turgor (Leyton-Puig et al., 2017, Tweten et al., 2017). In further support of this, yeast and mammalian systems also have acto-myosin network strongly accumulated at the endocytic spot (Collins et al., 2011, Yarar et al., 2005, Toshima et al., 2006, Picco et al., 2015). Therefore, actin has long been assumed to be a critical component of plant CME (Chen et al., 2011, Robatzek et al., 2006, Samaj et al., 2004). However, chronic and acute inhibition of actin dynamics demonstrated that actin perturbations have no visible influence on CME kinetics or efficiency. Furthermore, plants do not possess type 1 myosin (the class of myosin involved in yeast endocytosis), and, more importantly, actin or its associated proteins do not accumulate at the CME loci. This challenges all models that frame our current understanding on membrane cycling energetics under turgor.

The mechanism of plant CME membrane bending was found to follow the constant curvature model. In this model, the curvature could be generated by the continuous polymerization of clathrin (Bucher et al., 2018, Scott et al., 2018), therefore in plants it is possible that clathrin polymerization energy, in addition to other membrane deforming proteins, might provide enough force to overcome the turgor pressure. It is noteworthy that plant-specific mechanism of membrane bending must overcome turgor pressures higher than found in yeast, while producing larger CCVs (60 $\mathrm{nm}$ compared to $36 \mathrm{~nm}$ in Saccharomyces cerevisiae (Smaczynska-de et al., 2010)) and in a more rapid manner (33-42 s compared to 75-135 s (Lu et al., 2016)).

It is possible that during the independent evolution of multi-cellularity in plants and animals, alternate membrane deformation mechanisms co-evolved in accordance to the differences in cell-cell adhesion, signalling and polarity between the model systems (Eaton and Martin-Belmonte, 2014). Therefore, screening for other membrane modifying proteins and studying their activity would enable us to discover this plant specific substitution mechanism for membrane deformation during CME. 


\section{Active role of actin-mediated endosomal movement in endocytosis}

Our observations established that while actin does not accumulate at sites of CME and it is not required for CME events at the PM, it mediates directional movement of CVVs and EEs. However, during actin disruption, endocytosed membrane still reached the aggregated EE/TGN structures. This suggests that a passive Brownian motion of the freed CCVs is sufficient for the eventual reaching of CCVs the EEs.

However, direct examination of protein cargos and their mis-localization following actin disruption suggested that actin-mediated EE mobility is a key requirement for a specific cargo sorting. In support of this, we observed a strong spatiotemporal relationship between the actin filaments dynamic at the vicinity of the PM and CME events (Figure 7). Further to this, we also observed a significant correlation between the termination of CME events at the PM and the targeted movement of the TGN/EE passing below (Figure 7).

This suggests a so far unappreciated active role of fine actin filament dynamics as well as the directional, actin-mediated TGN/EE movement in mediating CME events at the PM and organizing early post-endocytic trafficking.

\section{Delayed uncoating of clathrin-coated vesicles on route to endosomes}

In both yeast and animal cellular systems endocytic vesicles uncoat rapidly after the scission event with aid of auxillin and HSC70 proteins (Bocking et al., 2011, Krantz et al., 2013). However, there is some debate as to whether uncoating is an all-or-nothing process (Schröter et al., 2016, Trahey and Hay, 2010). The uncoating process in plants has not been studied in any detail; while there are auxillin-like proteins, their deletion does not produce as strong effects on CME as observed in mammalian systems (Adamowski et al., 2018). This rises a possibility that plants have different mechanisms to uncoat the CCVs or uncoating is less crucial than assumed.

Our in planta live imaging show that CCVs had a prolonged retention of their clathrin coat, sometimes even until CCVs reach the EE (figure 7). This opens a large scope for possible coat functions in CCV - EE fusions. Notably, not all constituents of the CCV coat were retained at the same time, as demonstrated by observations of CCVs that lost the plant-specific EAP TPLATE, while still retaining the clathrin coat. Such a sequential removal of $\mathrm{CCV}$ coat components is concordant to the Ark1-Prk1synaptojanin mediated uncoating of CCVs observed in yeast (Boettner et al., 2011, 
Sekiya-Kawasaki et al., 2003, Toret et al., 2008) but retaining the clathrin coat till the CCVs fusion with the endosomes is unheard of in other systems.

In summary, these observations revealed sequential and severely delayed uncoating or even no loss of clathrin coat on the way of endocytic vesicles to the early endosomes, which is in stark contrast with our current models of CME.

\section{Conclusions}

Here we present a detailed investigation into the mechanisms of CME progression from the initial invagination formation to its fusion with the endosomes thereby greatly advancing our current knowledge of the mechanism of plant CME. Plant CME follows the constant curvature model of $\mathrm{CCV}$ formation occurring much faster and generating much larger vesicles, than yeast systems, of predominantly hexagonal type. Contrary to current paradigm, plant $\mathrm{CME}$ does not require actin suggesting that plants have evolved a unique mechanism of membrane bending against turgor. Actin, nonetheless, is important in post-endocytoic events for movement of EEs and proper sorting of cargos. Importantly, the presence of dynamic fine actin filaments and passing of mobile EE below the PM has a significant correlation with an increased rate of CME, thus highlighting an unsuspected role of actin-mediated endosome movement in mediating CME at the PM and "collecting" the post-endocytic vesicles. The strongly delayed uncoating and sequential removal of coat components is another unique feature of plant CME. These observations in complex, multi-cellular organs also provide unprecedented insight into higher order interactions, which are otherwise absent in unicellular models. Altogether, this study shows that despite the presence of evolutionary conserved components, plant CME is mechanistically unique, presumably reflecting an independent evolution of multicellularity in plants versus other models. 


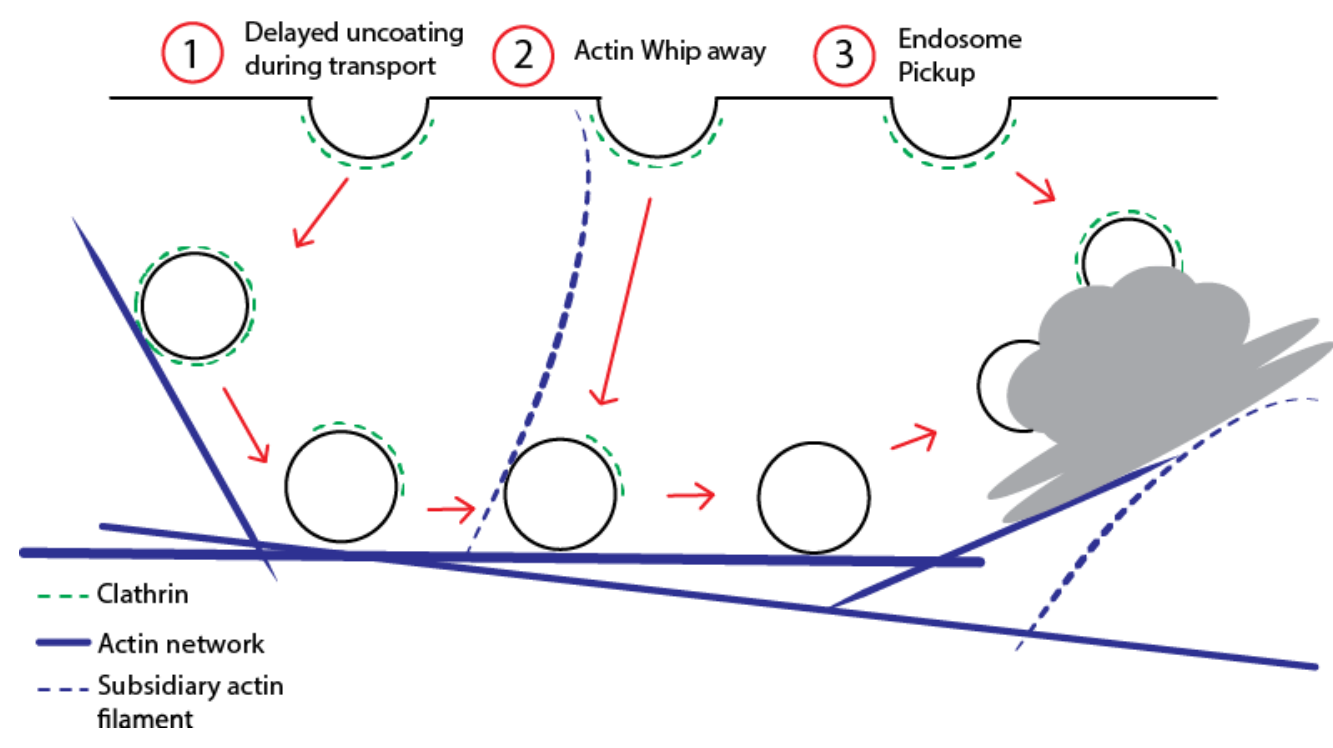

Figure 7: Model for post-endocytic trafficking of CCVs

Trafficking of the fully developed CCVs and the EE/TGN compartments along actin represented in different scenarios 1) Delayed sequential uncoating of the CCV during the transport to the EE/TGN 2) Actin subsidiary filament whipping away the CCV after scission transporting it to the EE/TGN 3) EE/TGN directly picking up the CCV after scission. 


\section{Contact for reagent and resource sharing:}

Further information and requests for resources and reagents should be directed to and will be fulfilled by the Lead Contact, Jiri Friml (jiri.friml@ist.ac.at)

\section{Experimental model and subject details:}

\section{$\underline{\text { Materials }}$}

The Arabidopsis thaliana genes studied and their corresponding accession numbers: Fim1 - AT4G26700, CLC2 - AT2G40060, Drp1C - AT1G14830, TplateAT3G01780, VHA-a1 - At2g28520, PIN2 - AT5G57090, FLS2 - AT5G46330, Ax12 AT4G12770, AP2A1 -AT5G22770. All lines used are from Arabidopsis thaliana: $p C L C 2:: C L C 2-G F P$ and pDRP1C::DRP1C-GFP (Konopka et al., 2008); pRPS5A::CLC2-RFP, pLAT52p::TPLATE-GFP $\quad \mathrm{x} \quad$ pRPS5A::AP2-RFP and pLAT52::TPLATE-GFP x pRPS5::CLC2-RFP tplate (Gadeyne et al., 2014); p35S::Fim1-GFP and 35S::ABD2-GFP (Wang et al., 2004); p35S:: mTalin-GFP (Kost et al., 1998); p35S::Lifeact-VENUS (lifeact gene fused in the $\mathrm{N}$ - terminus driven by 35s promoter, a gift from Matyas Fendrych and Moritz Nowack); $p 35 S:: S T-R F P \mathrm{x}$ pCLC2::CLC2-GFP (Ito et al., 2012); pVHA-al::VHA-al-GFP (Dettmer et al., 2006); pFLS2::FLS2-GFP x pUBQ10::mRFP ARA7 (Beck et al., 2012); pPIN2::PIN2Dendra eirl-1 (Salanenka et al., 2018); XVE>>Axl2 x pPIN2::PIN2-Dendra (Adamowski et al., 2018); p35S::ABD2-GFP x p35S::CLC2-mKO was generated by crossing p35S::CLC2-mKO (Naramoto et al., 2010) with p35S::ABD2-GFP; pPIN2::PIN2-GFP х $p 35 S:: A R A 7-m R F P$ was generated by crossing pPIN2::PIN2GFP (Xu and Scheres, 2005) with $p 35 S:: A R A 7-m R F P$ (Ueda et al., 2004); 35s::AP2A1GFP x $p R P S 5 A:: C L C$-tagRFP was generated by crossing 35s::AP2A1-GFP (Di Rubbo et al., 2013) with $p R P S 5 A:: C L C$-tagRFP plants and the F1 progeny were used.

\section{Seedling growth conditions}

Seeds were sown on $1 / 2$ MS Agar medium agar, with $1 \%$ (w/v) sucrose, stratified for 23 days and then grown at $21^{\circ} \mathrm{C}$ in a $16 \mathrm{~h} / 8 \mathrm{~h}$ day/night cycle. Seedlings to examine roots were grown for 3 or 7 days, seedlings to examine the hypocotyl seedlings were grown for 3 days in dark conditions.

\section{$\underline{\text { Root cell culture - maintenance }}$}


Arabidopsis (Col-0) root-derived suspension was obtained from Eva Kondorosi (Gifsur-Yvette, France). The suspension culture is maintained in growth medium (GM) of pH5.7 containing $4.25 \mathrm{~g} / \mathrm{l}$ of MS salts (Sigma M5524), 30g/l of sucrose, $0.250 \mathrm{mg}$ of 2,4D, 0.015mg of kinetin and 2ml Vitamin B5 stock (100ml stock contains $0.1 \mathrm{~g}$ nicotininc acid, $0.1 \mathrm{~g}$ pyridoxine $\mathrm{HCl}, 1 \mathrm{~g}$ thiamine $\mathrm{HCl} .10 \mathrm{~g}$ myo-inositol)

\section{Materials Used:}

LatrunculinB, $\beta$-estradiol, MS powder and all chemicals used for metal replicas and resin embedding were from Sigma Aldrich; with the exceptions of EM grade glutaraldehyde and pioloform (Agar Scientific Ltd., Stansted, UK), Osmium tetroxide (Electron Microscopy Sciences, Hatfield, PA), Acetone and polyethylene glycol (Merck, Darmstadt, Germany), picric acid (Fluka GmbH, Buchs, Switzerland), Uranyl acetate (AL-Labortechnik E.U., Amstetten, Austria). Jasplakinolide was from Santa Cruz Biotechnology, Cellulase from Serva, Macerozyme from Yakult pharmaceuticals, Aclar ${ }^{\circledR}$ foil from Ted Pella Inc. (Redding, CA), Aluminium planchettes and sapphire disks from Wohlwend (Sennwald, Switzerland), Cryo-vials from Biozym GmbH (Vienna, Austria), Glass cover slips from Roth (Karlsruhe, Germany), Maxtaform H15 finder grids from Science Services GmbH (München, Germany) and Platinum and carbon rods were from Leica Microsystems (Vienna, Austria).

\section{Methods}

\section{Protoplast preparation and plating}

3-day old Arabidopsis suspension cultured cells were used. Protoplast isolation from the cells was carried out as described by Dóczi and colleagues (Doczi et al., 2011). Isolated protoplasts were left at $4^{\circ} \mathrm{C}$ overnight. They were then plated onto glass coverslips (Ø $12 \mathrm{~mm}$ ), which were pre-coated with carbon to a thickness of $10 \mathrm{~nm}$ and treated with Poly-L-Lysine (PLL) overnight at $4{ }^{\circ} \mathrm{C}$ and incubated at room temperature for 4 hours. The protoplasts plated onto coverslips were then centrifuged at $800 \mathrm{rpm}$ for 5 mins to aid protoplast adhesion to the coverslips.

\section{Metal replica electron microscopy}

The plated protoplasts were washed in PBS equilibrated to room temperature and the extraction solution (1\% Triton X-100 in PIPES-EGTA-magnesium buffer (PEM; 100 mM PIPES, $1 \mathrm{mM}$ EGTA, $1 \mathrm{mM} \mathrm{MgCl}_{2}$, pH 6.9) plus $1 \%$ high-MW polyethylene 
glycol (PEG; $20 \mathrm{kDa}$ ) and $2 \mu \mathrm{M}$ phalloidin $\pm 2 \mu \mathrm{M}$ taxol) was applied for 4 mins. Samples were then washed three times in PEM plus 1\% PEG for $1 \mathrm{~min}$ and then fixed in $2 \%$ Glutaraldehyde in phosphate buffer (PB) for 20 mins. After washing in distilled water, samples were treated with $0.1 \%$ tannic acid in water $(\mathrm{w} / \mathrm{v})$ for $20 \mathrm{mins}$ at room temperature and $0.2 \%$ uranyl acetate in water $(\mathrm{w} / \mathrm{v})$ for $20 \mathrm{mins}$ at room temperature. Samples were then 'critical point dried' as described by Svitkina and colleagues (Svitkina, 2007). Samples were then fixed on SEM specimen mounts by means of carbon conductive adhesive tabs ( $\varnothing 12 \mathrm{~mm}$ ), and gold-coated to a thickness of $5 \mathrm{~nm}$ by rotary shadowing at a $45^{\circ}$ angle using a ACE600 coating device (Leica Microsystems).

\section{$\underline{\text { Resin embedding ultrastructure analysis }}$}

Protoplasts were plated onto Aclar® foil, which had been coated with PLL overnight at $4{ }^{\circ} \mathrm{C}$, and incubated at room temperature for 4 hours. After a wash in phosphate buffered saline (PBS; 0.1M, 0.9\% NaCl, $\mathrm{pH} 7.4$ ), the protoplasts were incubated in one of the following solutions for 30 mins at room temperature: GM buffer or hyperosmolar buffer (75mM Mannitol in GM buffer). Protoplasts were then fixed in $2 \%$ formaldehyde plus $2.5 \%$ glutaraldehyde and $15 \%$ of a saturated solution of picric acid in phosphate buffer $(\mathrm{PB} ; 0.1 \mathrm{M}, \mathrm{pH} 7.4)$ for 30 mins at room temperature. The protoplasts were then washed with PB buffer and then incubated with $0.5 \%$ tannic acid in PB (w/v) for 1 hour at $4^{\circ} \mathrm{C}$, then $1 \%$ osmium tetroxide in PB (w/v) for 30 mins at $4^{\circ} \mathrm{C}$ and then $1 \%$ uranyl-acetate in water (w/v) overnight at $4^{\circ} \mathrm{C}$. Protoplasts were then contrast-enhanced with Walton's lead aspartate for 30 mins at $60^{\circ} \mathrm{C}$, dehydrated in graded ethanols and anhydrous acetone, and embedded in epoxy resin (Durcupan ${ }^{\mathrm{TM}}$ ACM). Serial ultrathin sections of $40 \mathrm{~nm}$ were cut with an ultramicrotome UC7 (Leica Microsystems), collected onto Formvar-coated copper slot grids and stained with $1 \%$ aqueous uranyl acetate and $0.3 \%$ lead citrate.

\section{$\underline{\text { Treatment conditions }}$}

All the treatments were carried out at room temperature in $1 / 2$ MS medium containing $1 \%(\mathrm{w} / \mathrm{v})$ sucrose. Jasp and LatB treatments of the seedlings were carried out by dissolving the compounds in DMSO, and then diluting to the working concentration with liquid $1 / 2 \mathrm{MS}$ and $1 \%$ sucrose solution. Specific concentrations and duration of treatments are defined in the relevant figure legends. Throughout imaging experiments, the seedlings were kept in the mock or treatment solutions, with the exception of FM4- 
64 uptake experiments. To induce the overexpression of Auxilin2, 2-day old seedlings expressing $X V E>>A x l 2$ x pPIN2::PIN2-Dendra were induced by transferring them to solid $1 / 2$ AM with $1 \%$ sucrose plate supplemented with $2 \mu \mathrm{M} \beta$-estradiol. The seedlings were continuously under chemical induction during subsequent imaging.

To examine the uptake of FM4-64, following the actin/mock treatment, 3-day old seedlings were incubated with $2 \mu$ M FM4-64 dissolved in liquid $1 \frac{2}{2}$ MS with $1 \%$ sucrose medium for 2 mins. The seedlings were then washed twice before being imaged. To examine Flagellin uptake, 3-day-old etiolated seedlings were incubated in $10 \mu \mathrm{M}$ flg22 in liquid $1 / 2$ MS with $1 \%$ sucrose medium for 30 mins. Flagellin treatment was continuously present during imaging.

\section{Microscopy}

\section{Confocal microscopy}

To determine the endocytic rate of PIN2, photo conversion and imaging of photo converted PIN2-Dendra at the PM was conducted using a Zeiss LSM700 vertical confocal microscope equipped with a Plan-Apochromat 20x / NA 0.8 air objective; as previously described (von Wangenheim et al., 2017). The whole root was photo converted from green to red by a 2 mins excitation by UV light, from a mercury arc lamp and through a DAPI filter. The growing root was tracked for 4 hours with the 'Tip Tracker' software (von Wangenheim et al., 2017) and the loss of intensity of the converted red PIN2-Dendra signal was imaged through all roots at $15 \mathrm{~min}$ intervals over different planes of the entire epidermal tissue layer. Imaging of FM4-64 dye uptake, PIN2 co-localization experiments in root meristem, and imaging of CLC2-GFP localisation in etiolated hypocotyls were done using a LSM700 inverted confocal microscope; with a Plan-Apochromat 40x / NA 1.3 water objective. Root hairs were imaged with a Zeiss LSM880 upright confocal system, using a Plan-Apochromat 40x / NA 1.2 water objective and AiryScan detector.

\section{$\underline{\text { TIRF microscopy }}$}

Roots of 7-day-old seedlings or hypocotyls of 3-day-old etiolated seedlings were imaged with a Olympus IX83 inverted microscope equipped with a Cell^TIRF module using a OLYMPUS Uapo N 100x/1.49 Oil TIRF objective. A quad line beam splitter emission filter (Chroma) in combination with an EM-CCD camera (Hamamatsu) was used to collect images. Excitation wavelengths were 488 for GFP tags and $561 \mathrm{~nm}$ for 
RFP tags. Time-lapse imaging in the hypocotyl was done on the epidermal cells that are closet to the root-hypocotyl junction, after cutting the cotyledon. Single channel images were collected at 2 frames per second. Dual channel imaging was done sequentially at the frame rate as specified in the figures/movies.

Roots were prepared for imaging as previously described by (Johnson and Vert, 2017) with an additional step of sealing the coverslip on to a microscope slide with nail polish. Single channel images were collected at 1 frame per second for either 301 or 601 frames. Dual channel images were collected sequentially in the GFP and RFP channels at a rate of 1 frame per second for 601 frames.

\section{Electron Microscopy:}

To examine the metal replicas of unroofed protoplasts a Zeiss FE-SEM Merlin VP Compact was used. An accelerating voltage of $0.5-5 \mathrm{kV}$ was applied under high vacuum condition and In-lens duo detector was used for image recording. For transmission electron microscopy of resin embedded samples, the protoplasts were examined and imaged at an accelerating voltage of $80 \mathrm{kV}$ in a Thermo Ficher TEMTecnai10 equipped with EMSIS Megaview G3 camera.

\section{Processing and quantification}

\section{CCSs population ultrastructural analysis:}

The classification of the SEM images of the CCSs after metal replica was done manually using Fiji (NIH) and plotted using R. To study the invagination of CCSs at the PM, TEM images of CCSs after resin embeddeding and sectioning of protoplasts were visually examined and classified using Fiji (NIH).

\section{$\underline{\text { TIRF-M Image Analysis: }}$}

Time series movies were subjected to just the particle detection and tracking programs of the cmeAnalysis package, as previously described (Johnson and Vert, 2017). For single channel analysis; only tracks which were not present in the first or last 10 frames, or within 10 pixels of the edge of the movie and persisted for 5 of more frames were considered for further analysis. For dual channel analysis, a master/slave detection approach was used, where the master had to satisfy the aforementioned criteria, but also required the slave channel to be present for more than 5 frames. Density calculations were made by imposing a $100 \times 100$ pixel region of interest (ROI) in the center of the 
movie. All the tracks within this ROI were used to produce an average density over 100 frames of the movie, where the middle frame was used as a reference and 50 frames before and after were used. To produce fluorescence profiles of the movies, all tracks from the experiments were combined, and tracks with the overall mean $+/-3$ frames were selected, and their fluorescence was normalized and combined to produce a mean fluorescence profile. For dual channel images, to produce a departure plot, the master tracks mean +/- 3 frames were aligned to their end point, and the slave channel fluorescence signal was also plotted. The endosome pickup analysis was conducted by first tracking the endocytosis spots with the single channel TIRF-M image analysis, and then tracking the larger endosome spots with TrackMate (Tinevez et al., 2017). To accurately track the endosomes, some of the movies were subjected to histogram matching bleaching correction. Only endosomes, which had a trajectory displacement greater than 10 pixels and not present within the first and last 10 frames of the movie were used for analysis. A 30 pixel ROI was created which centered on the co-ordinates of the endosome, and followed the endosome trajectory over time. Endocytosis tracks present in this mobile ROI were counted and the percentage of tracks ending in this ROI were calculated. To generate control endosome track; endosomes were labeled with a identifying number based on their order of detection, if the endosomes first coordinate was located in the upper left quarter of the image, 50 pixels were add to its $x$ axis if its identifying label was odd, or 50 pixels to its y axis if it was an even labeled track. If the endosome was located in the upper right quarter of the movie, 50 pixels were subtracted from its x co-ordinates if it was an odd track, even tracks had 50 pixels added to its y-axis. Tracks located in the bottom quarters of the movie had these additions of subtractions to the endosome coordinates reserved.

\section{Quantification of intensity profile:}

The intensity time-course of the endocytic foci marked by CLC2-GFP was processed as described in (Loerke et al., 2009), where the duration of the developmental phases were characterized based on the average change of intensity of the average trajectories over time. The average intensity values of CLC2-GFP measured over time in each root were normalized and subjected to smoothening, using a lowess curve. The phase transition was determined at the point when the slope drops $20 \%$ below the minimum slope. Post processing were made in Graphpad PRISM6.

\section{Population fitting:}


From the lifetimes of CLC2 tracks obtained, we first generated a normalized density histogram, $h(t)$, where $t$ denotes different possible lifetimes. As the only tracks with a lifetime of at least 5 frames were considered for analysis, the lifetimes have a specific lower bound $t_{\text {low }}=5 *$ frame rate. The lifetimes also have an upper bound $t_{\text {high }}$, corresponding to the total imaging time. Hence, we have $h(t)=0$, for $t<t_{\text {low }}$ and $t>t_{\text {high }}$. We choose a specific bin size, $\Delta t$, equal to the inverse of the frame rate, and obtain $h(t)$ as a discrete density function over a set of $N$ lifetimes (Adamowski and Friml), $1 \leq i \leq$ $N$, uniformly separated by $\Delta t$, between $t_{1}=t_{\text {low }}$ and $t_{\mathrm{N}}=t_{\text {high. }}$. Hence, $h\left(t_{\mathrm{i}}\right) \Delta t$ denotes the probability that the lifetime is in the interval $\left[t_{\mathrm{i}}, t_{\mathrm{i}+1}\right)$. We normalized the histogram to ensure the following normalization condition:

$$
\sum_{i=1}^{N} h\left(t_{i}\right) \Delta t=1
$$

As this distribution appears to arise from a mixture of exponential distributions. Therefore, to further characterize the distribution and extract various subpopulations that have different biological relevance, we fitted this distribution to a mixture of $n$ (truncated) exponential distributions. Each exponential subpopulation has a rate and fractional contribution to the mixture as free parameters. Hence, the free parameters to be inferred in the overall fitting function are the rates, $\lambda_{i}$, and the fractional contributions, $\mu_{i}, i \leq n$. As the sum of fractional contributions sum to $1, \sum \mu_{i}=1$, only $n$ 1 fractional contributions need to be inferred. For a fitting of $n$ exponential distribution mixture, the total free parameters to be inferred are $k_{\exp }(i)=2 n-1$. Each exponential distribution is truncated to be bounded between $t_{\text {low }}$ and $t_{\text {high }}$, resulting in the following truncated density function for the $i^{\text {th }}$ subpopulation:

$$
f_{i}(t)=\frac{p d f_{i}(t)}{c d f_{i}\left(t_{\mathrm{high}}\right)-c d f_{i}\left(t_{\mathrm{low}}\right)}=\frac{\lambda_{i} e^{-\lambda_{i} t}}{e^{-\lambda_{i} t_{\mathrm{low}}}-e^{-\lambda_{i} t_{\mathrm{high}}}},
$$

where $p d f_{i}(t)$ and $c d f_{i}(t)$ correspond to the probability density function and the cumulative distribution function of the $i^{\text {th }}$ exponential subpopulation. The overall fitting function takes the following form:

$$
\hat{h}(t)=\sum_{i=1}^{n} \mu_{i} f_{i}(t)
$$

with the additional constraint that $\sum \mu_{i}=1$. To perform the fitting, we minimize the following cost function: 


$$
\Lambda\left(\left\{\lambda_{i}, \mu_{i}\right\}\right)=\sum_{i=1}^{N}\left(h\left(t_{i}\right)-\hat{h}\left(t_{i}\right)\right)^{2},
$$

over the various possible parameter values $\lambda_{i}>0$, and $0 \leq \mu_{i} \leq 1$. This approach fits the normalized histogram density of the dataset to a mixture of truncated exponential density functions. To make sure that this constrained minimization problem does not result in local minima and return suboptimal parameter sets, we perform the minimization from various initial conditions and pick the best fit among the whole set of minimizations. In summary, we obtain

$$
\left\{\lambda_{i}^{*}, \mu_{i}^{*}\right\}=\underbrace{\operatorname{argmin}}_{\left\{\lambda_{i}, \mu_{i}\right\}} \Lambda\left(\left\{\lambda_{i}, \mu_{i}\right\}\right),
$$

with the value of the cost function at the inferred minimum being $\Lambda^{*}=\Lambda\left(\left\{\lambda_{i}^{*}, \mu_{i}^{*}\right\}\right)$. The values of AIC and BIC are obtained as $A I C=2 k_{\exp }+N \ln \left(\Lambda^{*} / N\right)$ and $B I C=k_{\exp } \ln N$ $+\mathrm{N} \ln \left(\Lambda^{*} / N\right)$. From the inferred fractions of the subpopulations, $\mu_{i}$, one can obtain the "true" contributions by correcting for the skewing that results from the truncation in the lifetimes to $t_{\text {low }}$ and $t_{\text {high. }}$ Let the true fraction of the $i^{\text {th }}$ subpopulation be $\mu_{i}^{0}$. Also, define $\omega_{i}=c d f_{i}\left(t_{\text {high }}\right)-c d f_{i}\left(t_{\text {low }}\right)$. We have the following for every $i$ :

$$
\mu_{i}=\frac{\omega_{i} \mu_{i}^{0}}{\sum_{j=1}^{n} \omega_{j} \mu_{j}^{0}}
$$

from which we can obtain the true fractions $\mu_{i}^{0}$ by solving a system of linear equations. We also performed fitting with a mixture of exponential and Rayleigh distributions instead of just exponential distributions, by making sure that the $i^{\text {th }}$ subpopulation is defined by a $p d f$ and $c d f$ that correspond to the Rayleigh distribution. The clathrin lifetime histogram subjected to Rayleigh and exponential distribution produced fittings for up to 5 populations. A previous study (Loerke et al., 2009) in mammals used Weibull distributions to fit clathrin pit lifetime data. However, fitting of a simulated dataset indicated that Weibull distributions overfit lifetime data, and do not infer the true underlying parameters corresponding to the subpopulations.

\section{PIN2 endocytic rate test:}

The time series images were processed using FIJI (NIH). Maximum intensity Zprojections of the epidermal PIN2 signal were used for analysis. A ROI covering majority of the meristem was drawn and the mean intensity of the photo-converted PIN2 signal was measured over time. 


\section{Velocity profile by organelle tracking:}

The time-lapse movies made on the movement of Golgi apparatus were processed using the Fiji plugin TrackMate (Tinevez et al., 2017). Tracks were profiled according to the maximum velocity exhibited by the organelle.

\section{$\underline{\text { Statistical analysis }}$}

Statistical analysis on data for CCP developmental progression, endocytic density and lifetimes was conducted using Graphpad Prism 6. Significance is defined by $p<0.05$.

Statistical analyses for PIN2 internalization rate between treatments were carried out using R version 1.1.383. We used a linear mixed effects regression (LMER) to test for the effect of treatment on PIN2 internalization rate. We modeled PIN2 PM intensity values as a function of two predictors: time and treatment and their interaction, and we included a random intercept for each root, which is common for longitudinal studies (Bolker et al., 2009). We assessed the model significance comparing it to a null (mean) model, and the significance of the interaction comparing to a model without interaction, using likelihood ratio tests. The modeling package lme4 was used (Bates et al., 2015). The model assumptions were checked by 1) testing for equal variance of the residuals 2) testing for normality of the residuals and 3) testing the normality of the random effects.

The number of samples and the repetitions of each experiment are all described in the respective figure main text and legends.

\section{Acknowledgements}

We thank Sebastian Bednarek, Daniel van Damme, Matyas Fendrych, Moritz Nowack, Hongjiang Li, and Jenny Russinova for gifting us material; Maciek Adamowski for valuable discussions; Ludek Lovicar and Vanessa Zheden from IST electron microscopy facility for technical support, Lenka Matejovicova for her help with statistics. We also thank, the IST Austria Bioimaging facility for use the microscopes. This project has received funding from the European Research Council (ERC) under the European Union's Horizon 2020 research and innovation 
programme (grant agreement No 742985) and Austrian Science Fund (FWF): I 3630-

B25. We would like to dedicate this publication to the memory of Chris Hawes, whose early electron microscopy work was a great inspiration to this work. 


\section{REFERENCES}

ADAMOWSKI, M. \& FRIML, J. 2015. PIN-dependent auxin transport: action, regulation, and evolution. Plant Cell, 27, 20-32.

ADAMOWSKI, M., NARASIMHAN, M., KANIA, U., GLANC, M., DE JAEGER, G. \& FRIML, J. 2018. A Functional Study of AUXILIN-LIKE1 and 2, Two Putative Clathrin Uncoating Factors in Arabidopsis. Plant Cell, 30, 700-716.

AGHAMOHAMMADZADEH, S. \& AYSCOUGH, K. R. 2009. Differential requirements for actin during yeast and mammalian endocytosis. Nature Cell Biology, 11, 1039-U283.

AVINOAM, O., SCHORB, M., BEESE, C. J., BRIGGS, J. A. \& KAKSONEN, M. 2015. ENDOCYTOSIS. Endocytic sites mature by continuous bending and remodeling of the clathrin coat. Science, 348, 1369-72.

AXELROD, D. 2001. Total internal reflection fluorescence microscopy in cell biology. Traffic, 2, 764-74.

BAI, T., SEEBALD, J. L., KIM, K. E., DING, H. M., SZETO, D. P. \& CHANG, H. C. 2010. Disruption of zebrafish cyclin G-associated kinase (GAK) function impairs the expression of Notch-dependent genes during neurogenesis and causes defects in neuronal development. BMC Dev Biol, 10, 7.

BAISA, G. A., MAYERS, J. R. \& BEDNAREK, S. Y. 2013. Budding and braking news about clathrin-mediated endocytosis. Current Opinion in Plant Biology, $16,718-725$.

BARBERON, M., ZELAZNY, E., ROBERT, S., CONEJERO, G., CURIE, C., FRIML, J. \& VERT, G. 2011. Monoubiquitin-dependent endocytosis of the iron-regulated transporter 1 (IRT1) transporter controls iron uptake in plants. Proc Natl Acad Sci U S A, 108, E450-8.

BATES, D., MÄCHLER, M., BOLKER, B. \& WALKER, S. 2015. Fitting Linear Mixed-Effects Models Using lme4. 2015, 67, 48 \%J Journal of Statistical Software.

BEAUZAMY, L., NAKAYAMA, N. \& BOUDAOUD, A. 2014. Flowers under pressure: ins and outs of turgor regulation in development. Annals of Botany, 114, 1517-1533.

BECK, K. A., CHANG, M., BRODSKY, F. M. \& KEEN, J. H. 1992. Clathrin assembly protein AP-2 induces aggregation of membrane vesicles: a possible role for AP-2 in endosome formation. J Cell Biol, 119, 787-96.

BECK, M., ZHOU, J., FAULKNER, C., MACLEAN, D. \& ROBATZEK, S. 2012. Spatio-temporal cellular dynamics of the Arabidopsis flagellin receptor reveal activation status-dependent endosomal sorting. Plant Cell, 24, 4205-19.

BOCKING, T., AGUET, F., HARRISON, S. C. \& KIRCHHAUSEN, T. 2011. Single-molecule analysis of a molecular disassemblase reveals the mechanism of Hsc70-driven clathrin uncoating. Nat Struct Mol Biol, 18, 295-301.

BOETTNER, D. R., CHI, R. J. \& LEMMON, S. K. 2011. Lessons from yeast for clathrin-mediated endocytosis. Nat Cell Biol, 14, 2-10.

BOLKER, B. M., BROOKS, M. E., CLARK, C. J., GEANGE, S. W., POULSEN, J. R., STEVENS, M. H. \& WHITE, J. S. 2009. Generalized linear mixed models: a practical guide for ecology and evolution. Trends Ecol Evol, 24, 127-35. 
BOULANT, S., KURAL, C., ZEEH, J. C., UBELMANN, F. \& KIRCHHAUSEN, T. 2011. Actin dynamics counteract membrane tension during clathrin-mediated endocytosis. Nature Cell Biology, 13, 1124-U158.

BRADY, R. J., DAMER, C. K., HEUSER, J. E. \& O'HALLORAN, T. J. 2010. Regulation of Hip1r by epsin controls the temporal and spatial coupling of actin filaments to clathrin-coated pits. J Cell Sci, 123, 3652-61.

BREUER, D., NOWAK, J., IVAKOV, A., SOMSSICH, M., PERSSON, S. \& NIKOLOSKI, Z. 2017. System-wide organization of actin cytoskeleton determines organelle transport in hypocotyl plant cells. Proc Natl Acad Sci U $S$ A, 114, E5741-E5749.

BUCHER, D., FREY, F., SOCHACKI, K. A., KUMMER, S., BERGEEST, J. P., GODINEZ, W. J., KRAUSSLICH, H. G., ROHR, K., TARASKA, J. W., SCHWARZ, U. S. \& BOULANT, S. 2018. Clathrin-adaptor ratio and membrane tension regulate the flat-to-curved transition of the clathrin coat during endocytosis. Nat Commun, 9, 1109.

BUSER, C. \& DRUBIN, D. G. 2013. Ultrastructural imaging of endocytic sites in Saccharomyces cerevisiae by transmission electron microscopy and immunolabeling. Microsc Microanal, 19, 381-92.

CHEN, X., IRANI, N. G. \& FRIML, J. 2011. Clathrin-mediated endocytosis: the gateway into plant cells. Current Opinion in Plant Biology, 14, 674-682.

COLEMAN, J., EVANS, D. \& HAWES, C. 1988. Plant coated vesicles. Plant, Cell and Environment, 11, 669-684.

COLLINS, A., WARRINGTON, A., TAYLOR, K. A. \& SVITKINA, T. 2011. Structural organization of the actin cytoskeleton at sites of clathrin-mediated endocytosis. Curr Biol, 21, 1167-75.

COSGROVE, D. J. 1993. How do plant cell walls extend? Plant Physiol, 102, 1-6.

DETTMER, J., HONG-HERMESDORF, A., STIERHOF, Y. D. \& SCHUMACHER, K. 2006. Vacuolar H+-ATPase activity is required for endocytic and secretory trafficking in Arabidopsis. Plant Cell, 18, 715-30.

DHONUKSHE, P., ANIENTO, F., HWANG, I., ROBINSON, D. G., MRAVEC, J., STIERHOF, Y. D. \& FRIML, J. 2007. Clathrin-mediated constitutive endocytosis of PIN auxin efflux carriers in Arabidopsis. Curr Biol, 17, 520-7.

DI RUBBO, S., IRANI, N. G., KIM, S. Y., XU, Z. Y., GADEYNE, A., DEJONGHE, W., VANHOUTTE, I., PERSIAU, G., EECKHOUT, D., SIMON, S., SONG, K., KLEINE-VEHN, J., FRIML, J., DE JAEGER, G., VAN DAMME, D., HWANG, I. \& RUSSINOVA, E. 2013. The clathrin adaptor complex AP-2 mediates endocytosis of brassinosteroid insensitive 1 in Arabidopsis. Plant Cell, 25, 2986-97.

DMITRIEFF, S. \& NEDELEC, F. 2015. Membrane Mechanics of Endocytosis in Cells with Turgor. Plos Computational Biology, 11.

DOCZI, R., HATZIMASOURA, E. \& BOGRE, L. 2011. Mitogen-activated protein kinase activity and reporter gene assays in plants. Methods Mol Biol, 779, 7992.

EATON, S. \& MARTIN-BELMONTE, F. 2014. Cargo sorting in the endocytic pathway: a key regulator of cell polarity and tissue dynamics. Cold Spring Harb Perspect Biol, 6, a016899.

EMONS, A. 1986. Coated pits and coated vesicles on the plasma membrane of plant cells. Eur. J. Cell Biol., 41, 57-64. 
FUJIMOTO, L. M., ROTH, R., HEUSER, J. E. \& SCHMID, S. L. 2000. Actin assembly plays a variable, but not obligatory role in receptor-mediated endocytosis in mammalian cells. Traffic, 1, 161-171.

FURTHAUER, M. \& GONZALEZ-GAITAN, M. 2009. Endocytic regulation of notch signalling during development. Traffic, 10, 792-802.

GADEYNE, A., SANCHEZ-RODRIGUEZ, C., VANNESTE, S., DI RUBBO, S., ZAUBER, H., VANNESTE, K., VAN LEENE, J., DE WINNE, N., EECKHOUT, D., PERSIAU, G., DE SLIJKE, E. V., CANNOOT, B., VERCRUYSSE, L., MAYERS, J. R., ADAMOWSKI, M., KANIA, U., EHRLICH, M., SCHWEIGHOFER, A., KETELAAR, T., MAERE, S., BEDNAREK, S. Y., FRIML, J., GEVAERT, K., WITTERS, E., RUSSINOVA, E., PERSSON, S., DE JAEGER, G. \& VAN DAMME, D. 2014. The TPLATE Adaptor Complex Drives Clathrin-Mediated Endocytosis in Plants. Cell, 156, 691-704.

GALWAY, M. E., RENNIE, P. J. \& FOWKE, L. C. 1993. Ultrastructure of the endocytotic pathway in glutaraldehyde-fixed and high-pressure frozen/freezesubstituted protoplasts of white spruce (Picea glauca). J Cell Sci, 106 ( Pt 3), 847-58.

GELDNER, N., FRIML, J., STIERHOF, Y. D., JURGENS, G. \& PALME, K. 2001. Auxin transport inhibitors block PIN1 cycling and vesicle trafficking. Nature, 413, 425-8.

GOH, L. K., HUANG, F., KIM, W., GYGI, S. \& SORKIN, A. 2010. Multiple mechanisms collectively regulate clathrin-mediated endocytosis of the epidermal growth factor receptor. J Cell Biol, 189, 871-83.

GONZALEZ-GAITAN, M. 2003. Endocytic trafficking during Drosophila development. Mech Dev, 120, 1265-82.

GRANGER, E., MCNEE, G., ALLAN, V. \& WOODMAN, P. 2014. The role of the cytoskeleton and molecular motors in endosomal dynamics. Semin Cell Dev Biol, 31, 20-9.

GREENER, T., ZHAO, X., NOJIMA, H., EISENBERG, E. \& GREENE, L. E. 2000. Role of cyclin G-associated kinase in uncoating clathrin-coated vesicles from non-neuronal cells. J Biol Chem, 275, 1365-70.

GROVE, J., METCALF, D. J., KNIGHT, A. E., WAVRE-SHAPTON, S. T., SUN, T., PROTONOTARIOS, E. D., GRIFFIN, L. D., LIPPINCOTT-SCHWARTZ, J. \& MARSH, M. 2014. Flat clathrin lattices: stable features of the plasma membrane. Mol Biol Cell, 25, 3581-94.

HIRST, J., SAHLENDER, D. A., LI, S., LUBBEN, N. B., BORNER, G. H. \& ROBINSON, M. S. 2008. Auxilin depletion causes self-assembly of clathrin into membraneless cages in vivo. Traffic, 9, 1354-71.

ITO, E., FUJIMOTO, M., EBINE, K., UEMURA, T., UEDA, T. \& NAKANO, A. 2012. Dynamic behavior of clathrin in Arabidopsis thaliana unveiled by live imaging. Plant J, 69, 204-16.

JELINKOVA, A., MALINSKA, K., SIMON, S., KLEINE-VEHN, J., PAREZOVA, M., PEJCHAR, P., KUBES, M., MARTINEC, J., FRIML, J.,

ZAZIMALOVA, E. \& PETRASEK, J. 2010. Probing plant membranes with FM dyes: tracking, dragging or blocking? Plant J, 61, 883-92.

JOHNSON, A. \& VERT, G. 2017. Single Event Resolution of Plant Plasma Membrane Protein Endocytosis by TIRF Microscopy. Front Plant Sci, 8, 612.

KAKSONEN, M. \& ROUX, A. 2018. Mechanisms of clathrin-mediated endocytosis. Nat Rev Mol Cell Biol, 19, 313-326. 
KAKSONEN, M., TORET, C. P. \& DRUBIN, D. G. 2005. A modular design for the clathrin- and actin-mediated endocytosis machinery. Cell, 123, 305-320.

KANG, B. H., NIELSEN, E., PREUSS, M. L., MASTRONARDE, D. \& STAEHELIN, L. A. 2011. Electron tomography of RabA4b- and PI-4Kbeta1labeled trans Golgi network compartments in Arabidopsis. Traffic, 12, 313-29.

KIRCHHAUSEN, T. 2000. Clathrin. Annu Rev Biochem, 69, 699-727.

KLEINE-VEHN, J., LANGOWSKI, L., WISNIEWSKA, J., DHONUKSHE, P., BREWER, P. B. \& FRIML, J. 2008. Cellular and molecular requirements for polar PIN targeting and transcytosis in plants. Mol Plant, 1, 1056-66.

KLIMA, A. \& FOISSNER, I. 2008. FM dyes label sterol-rich plasma membrane domains and are internalized independently of the cytoskeleton in characean internodal cells. Plant Cell Physiol, 49, 1508-21.

KONOPKA, C. A., BACKUES, S. K. \& BEDNAREK, S. Y. 2008. Dynamics of Arabidopsis dynamin-related protein $1 \mathrm{C}$ and a clathrin light chain at the plasma membrane. Plant Cell, 20, 1363-1380.

KOST, B., SPIELHOFER, P. \& CHUA, N. H. 1998. A GFP-mouse talin fusion protein labels plant actin filaments in vivo and visualizes the actin cytoskeleton in growing pollen tubes. Plant J, 16, 393-401.

KRANTZ, K. C., PUCHALLA, J., THAPA, R., KOBAYASHI, C., BISHER, M., VIEHWEG, J., CARR, C. M. \& RYE, H. S. 2013. Clathrin coat disassembly by the yeast Hsc70/Ssa1p and auxilin/Swa2p proteins observed by singleparticle burst analysis spectroscopy. J Biol Chem, 288, 26721-30.

KURAL, C., TACHEVA-GRIGOROVA, S. K., BOULANT, S., COCUCCI, E., BAUST, T., DUARTE, D. \& KIRCHHAUSEN, T. 2012. Dynamics of intracellular clathrin/AP1- and clathrin/AP3-containing carriers. Cell Rep, 2, 1111-9.

LAMPE, M., VASSILOPOULOS, S. \& MERRIFIELD, C. 2016. Clathrin coated pits, plaques and adhesion. J Struct Biol, 196, 48-56.

LEE, D. W., ZHAO, X., YIM, Y. I., EISENBERG, E. \& GREENE, L. E. 2008. Essential role of cyclin-G-associated kinase (Auxilin-2) in developing and mature mice. Mol Biol Cell, 19, 2766-76.

LEYTON-PUIG, D., ISOGAI, T., ARGENZIO, E., VAN DEN BROEK, B., KLARENBEEK, J., JANSSEN, H., JALINK, K. \& INNOCENTI, M. 2017. Flat clathrin lattices are dynamic actin-controlled hubs for clathrin-mediated endocytosis and signalling of specific receptors. Nat Commun, 8, 16068.

LOERKE, D., METTLEN, M., YARAR, D., JAQAMAN, K., JAQAMAN, H., DANUSER, G. \& SCHMID, S. L. 2009. Cargo and dynamin regulate clathrincoated pit maturation. PLoS Biol, 7, e57.

LU, R., DRUBIN, D. G. \& SUN, Y. D. 2016. Clathrin-mediated endocytosis in budding yeast at a glance. Journal of Cell Science, 129, 1531-1536.

MASSOL, R. H., BOLL, W., GRIFFIN, A. M. \& KIRCHHAUSEN, T. 2006. A burst of auxilin recruitment determines the onset of clathrin-coated vesicle uncoating. Proc Natl Acad Sci U S A, 103, 10265-10270.

MATTHEYSES, A. L., ATKINSON, C. E. \& SIMON, S. M. 2011. Imaging Single Endocytic Events Reveals Diversity in Clathrin, Dynamin and Vesicle Dynamics. Traffic, 12, 1394-1406.

MBENGUE, M., BOURDAIS, G., GERVASI, F., BECK, M., ZHOU, J., SPALLEK, T., BARTELS, S., BOLLER, T., UEDA, T., KUHN, H. \& ROBATZEK, S. 2016. Clathrin-dependent endocytosis is required for immunity mediated by 
pattern recognition receptor kinases. Proceedings of the National Academy of Sciences of the United States of America, 113, 11034-11039.

MERRIFIELD, C. J., FELDMAN, M. E., WAN, L. \& ALMERS, W. 2002. Imaging actin and dynamin recruitment during invagination of single clathrin-coated pits. Nature Cell Biology, 4, 691-698.

MERRIFIELD, C. J. \& KAKSONEN, M. 2014. Endocytic accessory factors and regulation of clathrin-mediated endocytosis. Cold Spring Harb Perspect Biol, 6, a016733.

MERRIFIELD, C. J., PERRAIS, D. \& ZENISEK, D. 2005. Coupling between clathrin-coated-pit invagination, cortactin recruitment, and membrane scission observed in live cells. Cell, 121, 593-606.

NARAMOTO, S., KLEINE-VEHN, J., ROBERT, S., FUJIMOTO, M., DAINOBU, T., PACIOREK, T., UEDA, T., NAKANO, A., VAN MONTAGU, M. C., FUKUDA, H. \& FRIML, J. 2010. ADP-ribosylation factor machinery mediates endocytosis in plant cells. Proc Natl Acad Sci U S A, 107, 21890-5.

PICCO, A., MUND, M., RIES, J., NEDELEC, F. \& KAKSONEN, M. 2015. Visualizing the functional architecture of the endocytic machinery. Elife, 4.

PLATTA, H. W. \& STENMARK, H. 2011. Endocytosis and signaling. Curr Opin Cell Biol, 23, 393-403.

ROBATZEK, S., CHINCHILLA, D. \& BOLLER, T. 2006. Ligand-induced endocytosis of the pattern recognition receptor FLS2 in Arabidopsis. Genes Dev, 20, 537-42.

ROBINSON, D. G. 1996. Clathrin-mediated trafficking. Trends in Plant Science, 1, 349-355.

ROBINSON, D. G. \& PIMPL, P. 2014. Clathrin and post-Golgi trafficking: a very complicated issue. Trends Plant Sci, 19, 134-9.

ROBINSON, M. S. 2015. Forty Years of Clathrin-coated Vesicles. Traffic, 16, 121038.

ROTH, T. F. \& PORTER, K. R. 1964. Yolk Protein Uptake in the Oocyte of the Mosquito Aedes Aegypti. L. J Cell Biol, 20, 313-32.

SALANENKA, Y., VERSTRAETEN, I., LOFKE, C., TABATA, K., NARAMOTO, S., GLANC, M. \& FRIML, J. 2018. Gibberellin DELLA signaling targets the retromer complex to redirect protein trafficking to the plasma membrane. Proc Natl Acad Sci U S A, 115, 3716-3721.

SALEEM, M., MORLOT, S., HOHENDAHL, A., MANZI, J., LENZ, M. \& ROUX, A. 2015. A balance between membrane elasticity and polymerization energy sets the shape of spherical clathrin coats. Nature Communications, 6.

SAMAJ, J., BALUSKA, F., VOIGT, B., SCHLICHT, M., VOLKMANN, D. \& MENZEL, D. 2004. Endocytosis, actin cytoskeleton, and signaling. Plant Physiol, 135, 1150-61.

SCHABER, J., ADROVER, M. A., ERIKSSON, E., PELET, S., PETELENZKURDZIEL, E., KLEIN, D., POSAS, F., GOKSOR, M., PETER, M., HOHMANN, S. \& KLIPP, E. 2010. Biophysical properties of Saccharomyces cerevisiae and their relationship with HOG pathway activation. European Biophysics Journal with Biophysics Letters, 39, 1547-1556.

SCHMID, S. L., SORKIN, A. \& ZERIAL, M. 2014. Endocytosis: Past, present, and future. Cold Spring Harb Perspect Biol, 6, a022509.

SCHRÖTER, S., BECKMANN, S. \& SCHMITT, H. D. 2016. Coat/Tether Interactions-Exception or Rule? 4. 
SCOTT, B. L., SOCHACKI, K. A., LOW-NAM, S. T., BAILEY, E. M., LUU, Q., HOR, A., DICKEY, A. M., SMITH, S., KERKVLIET, J. G., TARASKA, J. W. \& HOPPE, A. D. 2018. Membrane bending occurs at all stages of clathrincoat assembly and defines endocytic dynamics. Nat Commun, 9, 419.

SEKIYA-KAWASAKI, M., GROEN, A. C., COPE, M. J., KAKSONEN, M., WATSON, H. A., ZHANG, C., SHOKAT, K. M., WENDLAND, B., MCDONALD, K. L., MCCAFFERY, J. M. \& DRUBIN, D. G. 2003. Dynamic phosphoregulation of the cortical actin cytoskeleton and endocytic machinery revealed by real-time chemical genetic analysis. J Cell Biol, 162, 765-72.

SMACZYNSKA-DE, R., II, ALLWOOD, E. G., AGHAMOHAMMADZADEH, S., HETTEMA, E. H., GOLDBERG, M. W. \& AYSCOUGH, K. R. 2010. A role for the dynamin-like protein Vps1 during endocytosis in yeast. J Cell Sci, 123, 3496-506.

SOCHACKI, K. A. \& TARASKA, J. W. 2019. From Flat to Curved Clathrin: Controlling a Plastic Ratchet. Trends Cell Biol, 29, 241-256.

STACHOWIAK, J. C., BRODSKY, F. M. \& MILLER, E. A. 2013. A cost-benefit analysis of the physical mechanisms of membrane curvature. Nat Cell Biol, $15,1019-27$.

STAIGER, C. J., SHEAHAN, M. B., KHURANA, P., WANG, X., MCCURDY, D. W. \& BLANCHOIN, L. 2009. Actin filament dynamics are dominated by rapid growth and severing activity in the Arabidopsis cortical array. $J$ Cell Biol, 184, 269-80.

SVITKINA, T. 2007. Electron microscopic analysis of the leading edge in migrating cells. Methods Cell Biol, 79, 295-319.

TANCHAK, M. A., RENNIE, P. J. \& FOWKE, L. C. 1988. Ultrastructure of the partially coated reticulum and dictyosomes during endocytosis by soybean protoplasts. Planta, 175, 433-41.

TAYLOR, M. J., LAMPE, M. \& MERRIFIELD, C. J. 2012. A Feedback Loop between Dynamin and Actin Recruitment during Clathrin-Mediated Endocytosis. Plos Biology, 10.

TAYLOR, M. J., PERRAIS, D. \& MERRIFIELD, C. J. 2011. A high precision survey of the molecular dynamics of mammalian clathrin-mediated endocytosis. PLoS Biol, 9, e1000604.

TINEVEZ, J. Y., PERRY, N., SCHINDELIN, J., HOOPES, G. M., REYNOLDS, G. D., LAPLANTINE, E., BEDNAREK, S. Y., SHORTE, S. L. \& ELICEIRI, K. W. 2017. TrackMate: An open and extensible platform for single-particle tracking. Methods, 115, 80-90.

TORET, C. P., LEE, L., SEKIYA-KAWASAKI, M. \& DRUBIN, D. G. 2008. Multiple pathways regulate endocytic coat disassembly in Saccharomyces cerevisiae for optimal downstream trafficking. Traffic, 9, 848-59.

TOSHIMA, J. Y., TOSHIMA, J., KAKSONEN, M., MARTIN, A. C., KING, D. S. \& DRUBIN, D. G. 2006. Spatial dynamics of receptor-mediated endocytic trafficking in budding yeast revealed by using fluorescent alpha-factor derivatives. Proc Natl Acad Sci U S A, 103, 5793-8.

TRAHEY, M. \& HAY, J. C. 2010. Transport vesicle uncoating: it's later than you think. F1000 Biol Rep, 2, 47.

TWETEN, D. J., BAYLY, P. V. \& CARLSSON, A. E. 2017. Actin growth profile in clathrin-mediated endocytosis. Phys Rev E, 95, 052414. 
UEDA, T., UEMURA, T., SATO, M. H. \& NAKANO, A. 2004. Functional differentiation of endosomes in Arabidopsis cells. Plant J, 40, 783-9.

VAN DER VALK, P. \& FOWKE, L. 2011. Ultrastructural aspects of coated vesicles in tobacco protoplasts.

VIOTTI, C., BUBECK, J., STIERHOF, Y. D., KREBS, M., LANGHANS, M., VAN DEN BERG, W., VAN DONGEN, W., RICHTER, S., GELDNER, N., TAKANO, J., JURGENS, G., DE VRIES, S. C., ROBINSON, D. G. \& SCHUMACHER, K. 2010. Endocytic and secretory traffic in Arabidopsis merge in the trans-Golgi network/early endosome, an independent and highly dynamic organelle. Plant Cell, 22, 1344-57.

VIZCAY-BARRENA, G., WEBB, S. E. D., MARTIN-FERNANDEZ, M. L. \& WILSON, Z. A. 2011. Subcellular and single-molecule imaging of plant fluorescent proteins using total internal reflection fluorescence microscopy (TIRFM). Journal of Experimental Botany, 62, 5419-5428.

VON WANGENHEIM, D., HAUSCHILD, R., FENDRYCH, M., BARONE, V., BENKOVA, E. \& FRIML, J. 2017. Live tracking of moving samples in confocal microscopy for vertically grown roots. Elife, 6.

WAN, Y., ASH, W. M., 3RD, FAN, L., HAO, H., KIM, M. K. \& LIN, J. 2011. Variable-angle total internal reflection fluorescence microscopy of intact cells of Arabidopsis thaliana. Plant Methods, 7, 27.

WANG, X., LI, X., DENG, X., LUU, D. T., MAUREL, C. \& LIN, J. 2015. Singlemolecule fluorescence imaging to quantify membrane protein dynamics and oligomerization in living plant cells. Nat Protoc, 10, 2054-63.

WANG, Y. S., MOTES, C. M., MOHAMALAWARI, D. R. \& BLANCAFLOR, E. B. 2004. Green fluorescent protein fusions to Arabidopsis fimbrin 1 for spatiotemporal imaging of F-actin dynamics in roots. Cell Motil Cytoskeleton, 59, 79-93.

WATANABE, S., TRIMBUCH, T., CAMACHO-PEREZ, M., ROST, B. R., BROKOWSKI, B., SOHL-KIELCZYNSKI, B., FELIES, A., DAVIS, M. W., ROSENMUND, C. \& JORGENSEN, E. M. 2014. Clathrin regenerates synaptic vesicles from endosomes. Nature, 515, 228-33.

XU, J. \& SCHERES, B. 2005. Dissection of Arabidopsis ADP-RIBOSYLATION FACTOR 1 function in epidermal cell polarity. Plant Cell, 17, 525-36.

YARAR, D., WATERMAN-STORER, C. M. \& SCHMID, S. L. 2005. A dynamic actin cytoskeleton functions at multiple stages of clathrin-mediated endocytosis. Molecular Biology of the Cell, 16, 964-975.

YIM, Y. I., SUN, T., WU, L. G., RAIMONDI, A., DE CAMILLI, P., EISENBERG, E. \& GREENE, L. E. 2010. Endocytosis and clathrin-uncoating defects at synapses of auxilin knockout mice. Proc Natl Acad Sci U S A, 107, 4412-7.

YOSHINARI, A., FUJIMOTO, M., UEDA, T., INADA, N., NAITO, S. \& TAKANO, J. 2016. DRP1-Dependent Endocytosis is Essential for Polar Localization and Boron-Induced Degradation of the Borate Transporter BOR1 in Arabidopsis thaliana. Plant and Cell Physiology, 57, 1985-2000. 


\section{Supplementary Information}
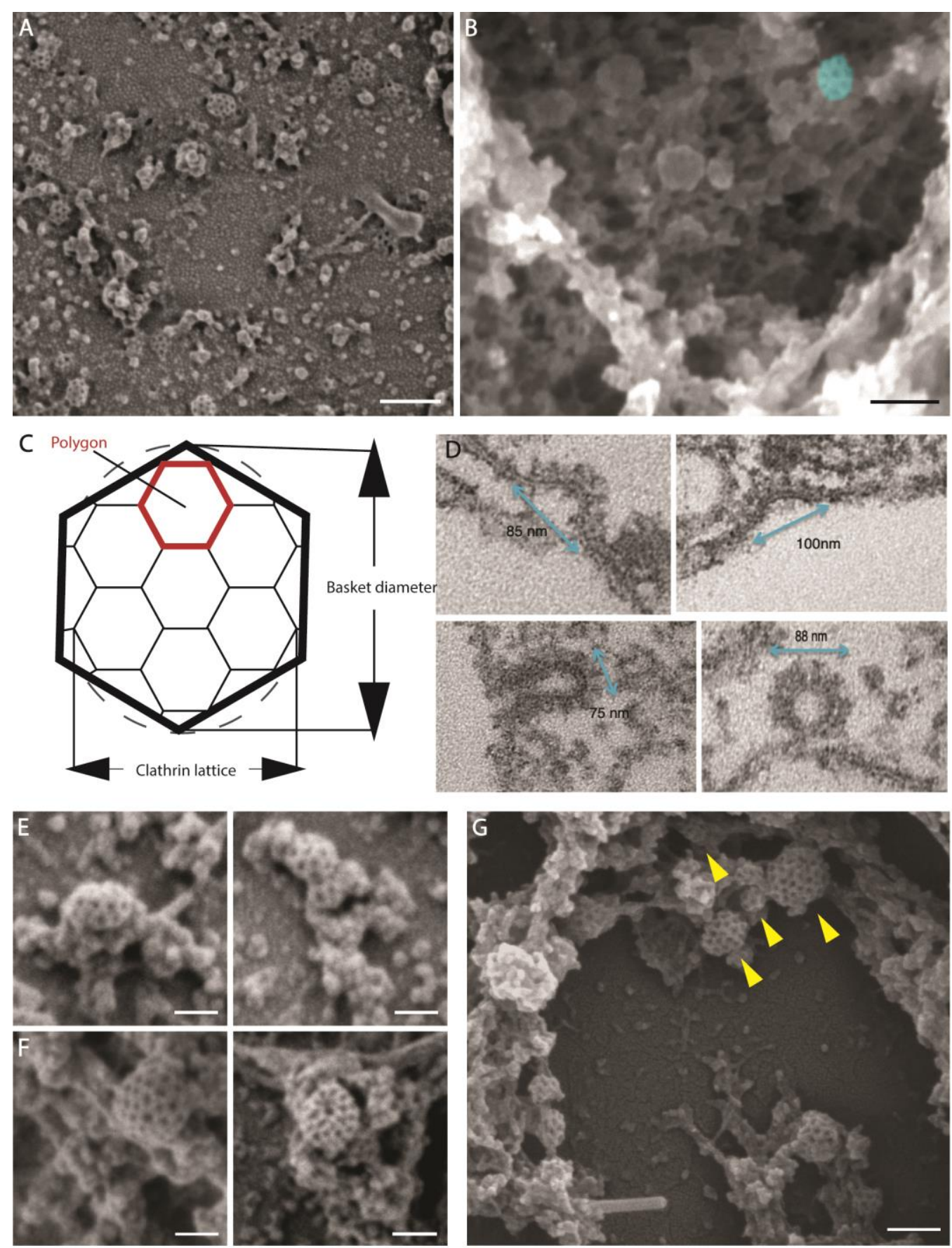

$\mathrm{H} \quad$ a) Constant curvature model

b) Constant area model

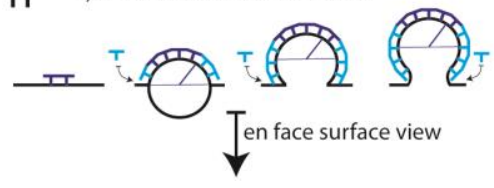

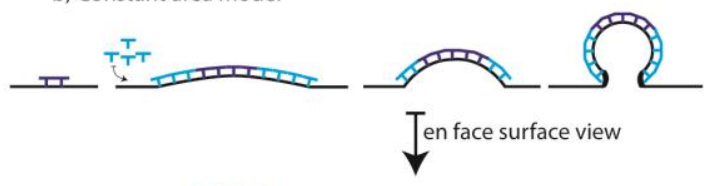

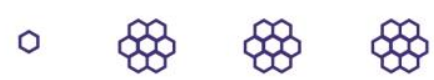
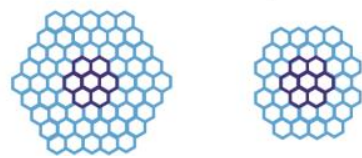

$\$ 3$

Figure S1. Related to Figure 1

\section{Ultrastructural characterization of clathrin-coated structures}


A) A representative SEM image of metal replica of protoplasts shows CCPs in varying stages of development at the PM. Scale bar: $200 \mathrm{~nm}$

B) An example SEM image depicting the cytoskeletal and endomembrane structures deeper in the cell with a single CCS marked in blue. Scale bar: $100 \mathrm{~nm}$.

C) An illustration depicting the en face surface view of the growing 'Clathrin lattice' of the most common - Hexagonal basket.

D) The TEM images showcasing the invagination event of the resin embedded and sectioned protoplasts under hyper osmotic condition. $\mathrm{N}=62$ sections with a total of 4 invagination events captured. Note that predominantly the irregular population of CCSs with diameter $>80 \mathrm{~nm}$ are captured.

E) - G) Example SEM images depicting arrangements of the CCSs in endomembrane structures. E) Multiple-fused CCSs F) Isolated CCSs of huge basket type. Scale bars: $75 \mathrm{~nm}$.

G) Aggregation of CCPs of distinct population types (indicated by arrows). Scale bar: $100 \mathrm{~nm}$.

H) Two models of clathrin-mediated membrane bending: The constant curvature model where the added clathrin bends the membrane and the en face surface view of the pit stays the same. The constant area model where the en face surface view of the pit converges from a flat lattice to a curved dome. 
A Sub-populations fitted to Weibull distributions

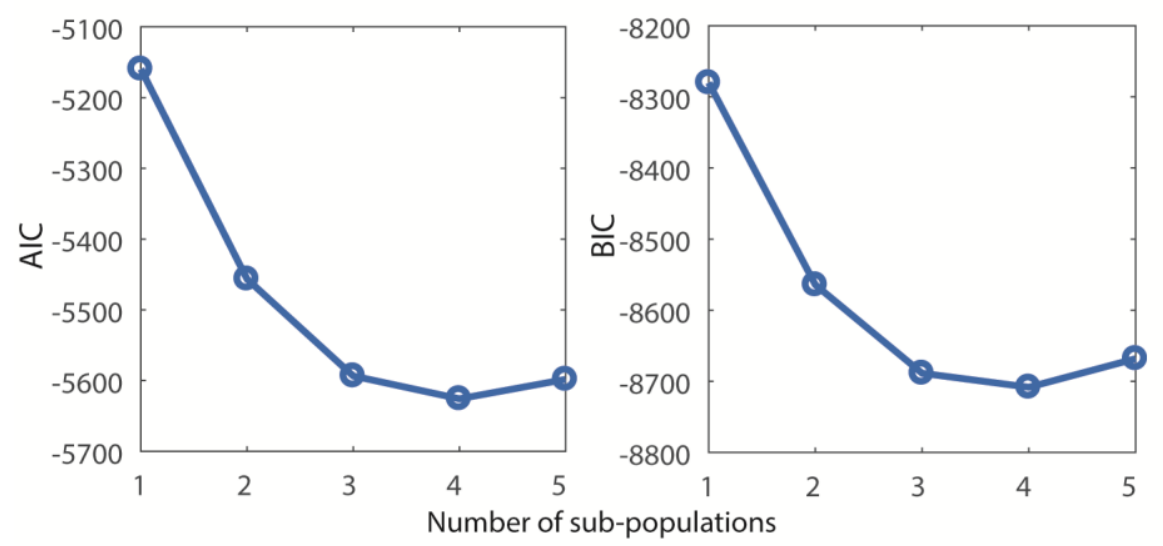

B Sub-populations fitted to exponential distributions
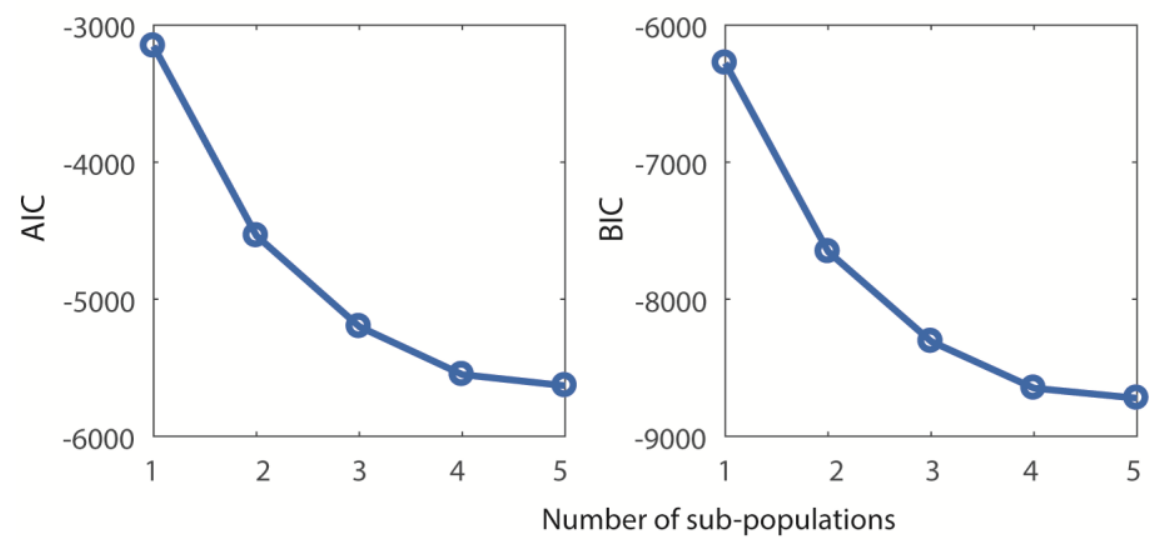

C Sub-populations fitted to mixed distributions of exponential and Rayleigh
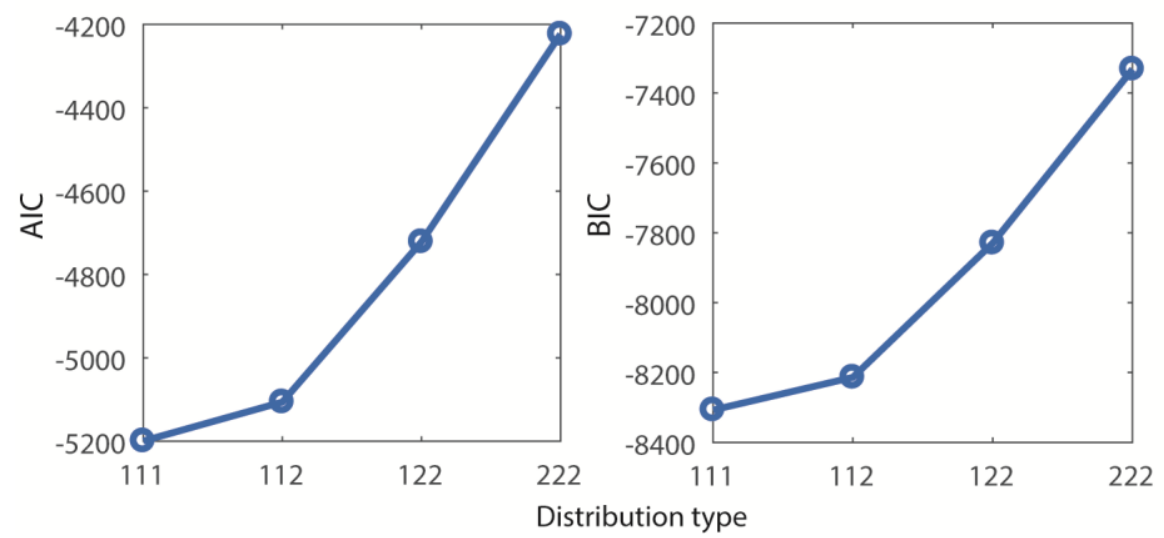

Figure S2. Related to Figure 2

\section{Goodness of fit analysis of clathrin sub-populations}

A) and B) AIC and BIC projecting the goodness of fit for the clathrin lifetime histogram subjected to fitting 1 to 5 sub-populations with Weibull distributions (A) or exponential distributions (B).

C) AIC and BIC projecting the goodness of fit for the clathrin lifetime histogram subjected to fitting 3 sub-populations with a both Rayleigh $(\lambda=2)$ and Exponential $(\lambda=1)$ distributions. Note that 3 exponential distributions produce the best fit. 

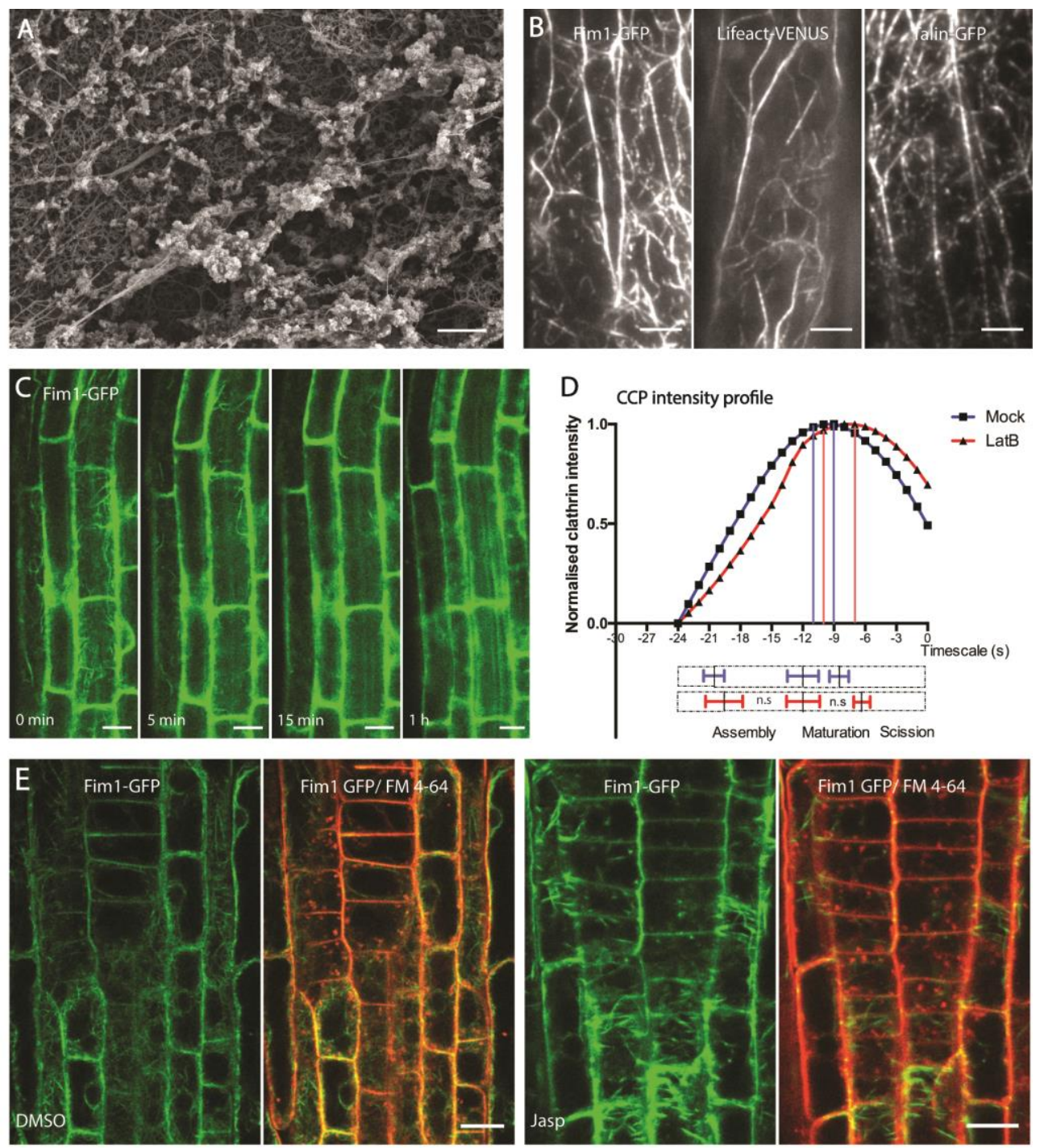

Figure S3. Related to Figure 3

\section{Localization and functional characterization of actin during endocytosis}

A) Example SEM image of unroofed protoplast showing the cytoskeletal and endomembranous structures tightly linked with other cellular components. Scale bar: 0.5 $\mu \mathrm{m}$.

B) Representative TIRF-M image showing the structure of cortical actin in hypocotyl expressing Fim1-GFP, Lifeact-VENUS and mTalin-GFP. Scale bar: $5 \mu \mathrm{m}$.

C) Representative confocal microscopy images of root epidermal cells expressing Fim1-GFP after LatB treatment. Note that majority of F-actin is depolymerized by 5 minutes. $\mathrm{N}=2$, with 7 roots. Scale bar: $15 \mu \mathrm{m}$

D) Smoothened CCP intensity profile of the CLC2-GFP population having the mean lifetimes of 17-24 s in root epidermal cells in the absence (black) or presence (red) of 
LatB (10 uM, 10 mins). $\mathrm{N}=6$ cells for mock, 487 trajectories; $\mathrm{N}=4$ cells for LatB treatment, 431 trajectories. The bottom bar plot represents the phase transitions computed individually from the trajectories of each root. The dotted bars represent the whole-time scale of CCP development; the solid lines with error bars mark the mean \pm $\mathrm{SD}$ of the transition point between phases. Note that there is no significant change in the length of the assembly or the maturation phase after LatB treatment. One-sided Mann-Whitney U test - for assembly $\mathrm{p}=0.44$ - for maturation $\mathrm{p}=0.08$.

E) Representative confocal microscopy images of root epidermis expressing Fim1GFP (marking actin) after mock of Jasp treatment ( $5 \mu \mathrm{M}, 60$ mins). 8 seedlings per condition. FM4-64 internalization occurs uninhibited despite deformities in actin filaments. Scale bars: $10 \mu \mathrm{m}$. 


\section{Supplementary movies:}

Movie S1: Dynamics of CCVs after actin perturbation. Related to Figure 3.

Dual channel TIRF-M imaging of hypocotyl epidermal cells expressing ABD2-GFP and CLC2-mKO after treatment with Jasp $-5 \mu \mathrm{M}$ for $1 \mathrm{~h}$. Movie shows the CCVs still forming and getting removed after the treatment comparable to the mock condition. Time label is in seconds. Scale bars: $5 \mu \mathrm{m}$.

\section{Movie S2: Actin mediated dynamics of the EE/TGN system. Related to Figure 4.}

Dual channel TIRF-M imaging of hypocotyl epidermal cells expressing ABD2-GFP and CLC2-mKO. The EE/TGN could be observed to be constantly moving along the actin filaments. Time label is in seconds. Scale bar: $2 \mu \mathrm{m}$.

Movie S3: Dynamics of the Golgi- EE/TGN after actin perturbation. Related to Figure 4.

Dual channel TIRF-M imaging of hypocotyl epidermal cells expressing ST-RFP and CLC2-GFP. The dynamics of the Golgi together with the EE/TGN after mock and LatB treatment $(10 \mu \mathrm{M} ; 1 \mathrm{~h})$ are shown. The local aggregation of Golgi - EE/TGN after LatB could be clearly observed. Time label is in seconds. Scale bar: $5 \mu \mathrm{m}$.

\section{Movie S4: Actin whipping away the CCVs.}

Dual channel TIRF-M imaging of hypocotyl epidermal cells expressing ABD2-GFP and CLC2-mKO. Spatial and temporal correlation between appearance of actin subsidiary filaments and the disappearance of CCVs could be seen. Time label is in seconds. Scale bar: $1 \mu \mathrm{m}$.

Movie S5: EE/TGN moving along actin picking up an endocytosed CCV. Related to Figure 5.

Dual channel TIRF-M imaging of hypocotyl epidermal cells expressing ABD2-GFP and CLC2-mKO. The CCV (arrowed) could be observed being collected by the EE/TGN (boxed) moving along the actin filament. Time label is in seconds. Scale bar: $1.5 \mu \mathrm{m}$. 
Dual channel TIRF-M imaging of hypocotyl epidermal cells expressing ST-RFP and CLC2-GFP. Aggregation of the endocytosed CCVs (arrowed) on the trans-side of the Golgi could be observed as the Golgi is moved along the cortical surface. Time label is in seconds. Scale bar: $2 \mu \mathrm{m}$.

Movie S7: Dynamic endosomes enhancing the local rate of CME termination.

\section{Related to figure 5.}

An example TIRF-M time lapse movie of root epidermal cells expression TPLATEGFP and CLC-tagRFP, but only the CLC channel is shown. The left shows the mobile experimental endosome tracks (red circles and blue tracks). The right shows the control endosome tracks. Red squares denote the endosome ROI, green circles denote tracks present within these endosomal ROI and are positive for both TPLATE and CLC. Black astricts denote the termination of CME. Scale bar, $5 \mu \mathrm{m}$.

\section{Movie S8: CCVs losing the coat.}

TIRF imaging of hypocotyl epidermal cells expressing ST-RFP and CLC2-GFP. CCVs (arrowed) that leave the membrane lose the clathrin coat before reaching EE/TGN. Time label is in seconds. Scale bar: $2 \mu \mathrm{m}$.

\section{Movie S9: Uncoating process as the CCVs reach the stationary EE/TGN. Related} to figure 6.

Dual channel TIRF imaging of hypocotyl epidermal cells expressing TPLATE-GFP $\mathrm{x}$ CLC2-RFP. CCVs (arrowed) moving to the stationary EE/TGN lose TPLATE signal by the time of reaching the EE/TGN compartment. Time label is in seconds. Scale bar: $1 \mu \mathrm{m}$.

\section{Movie S10: Uncoating process of a fully developed CCV. Related to figure 6.}

Dual channel TIRF imaging of hypocotyl epidermal cells expressing TPLATE-GFP $\mathrm{x}$ CLC2-RFP. CCV moving away from the PM after scission loses TPLATE signal before that of clathrin. Time label is in seconds. Scale bar: $1 \mu \mathrm{m}$. 


\section{Supplementary table 1:}

\begin{tabular}{|c|c|c|c|c|c|}
\hline \multicolumn{6}{|c|}{ System: Root } \\
\hline EAP & Treatment & $\begin{array}{l}\text { Average } \\
\text { Lifetime } \tau(\mathrm{s})\end{array}$ & $\begin{array}{l}\text { Density } \rho \\
(\# \text { foci/100 } \\
\left.\mu \mathrm{m}^{2}\right)\end{array}$ & $\begin{array}{l}\mathrm{N}=\text { number } \\
\text { of cells; } \\
\text { tracks }\end{array}$ & Significance \\
\hline \multirow[t]{4}{*}{$\begin{array}{l}\text { CLC2- } \\
\text { GFP }\end{array}$} & Mock & $21.93 \pm 2.42$ & $87.05 \pm 12.47$ & $\begin{array}{l}5 \text { cells; } \\
32990 \\
\text { tracks }\end{array}$ & \multirow[t]{2}{*}{ ns $(\tau ; \rho)$} \\
\hline & LatB & $20.66 \pm 3.51$ & $87.47 \pm 3.854$ & $\begin{array}{l}4 \text { cells; } \\
25517 \\
\text { tracks }\end{array}$ & \\
\hline & Mock & $24.96 \pm 6.33$ & $88.76 \pm 8.17$ & $\begin{array}{l}3 \text { cells; } \\
17901 \\
\text { tracks }\end{array}$ & \multirow[t]{2}{*}{ ns $(\tau ; \rho)$} \\
\hline & Jasp & $23.93 \pm 3.00$ & $81.61 \pm 9.17$ & $\begin{array}{l}6 \text { cells; } \\
40227 \\
\text { tracks }\end{array}$ & \\
\hline \multirow[t]{2}{*}{$\begin{array}{l}\text { TPLATE- } \\
\text { GFP }\end{array}$} & Mock & $22.64 \pm 2.261$ & $90.27 \pm 10.81$ & $\begin{array}{l}5 \text { cells; } \\
30577 \\
\text { tracks }\end{array}$ & \multirow[t]{2}{*}{ ns $(\tau ; \rho)$} \\
\hline & LatB & $25.20 \pm 2.80$ & $83.53 \pm 16.02$ & $\begin{array}{l}4 \text { cells; } \\
19259 \\
\text { tracks }\end{array}$ & \\
\hline \multirow[t]{4}{*}{$\begin{array}{l}\text { Drp1C- } \\
\text { GFP }\end{array}$} & Mock & $25.67 \pm 2.89$ & $50.97 \pm 8.833$ & $\begin{array}{l}6 \text { cells; } \\
27163 \\
\text { tracks }\end{array}$ & \multirow[t]{2}{*}{ ns $(\tau ; \rho)$} \\
\hline & LatB & $26.26 \pm 2.14$ & $71.91 \pm 31.46$ & $\begin{array}{l}4 \text { cells; } \\
17923 \\
\text { tracks }\end{array}$ & \\
\hline & Mock & $27.52 \pm 2.64$ & $68.19 \pm 10.95$ & $\begin{array}{l}3 \text { cells; } \\
11611 \\
\text { tracks }\end{array}$ & \multirow[t]{2}{*}{$\begin{array}{l}\text { ns }(\tau) ; \\
\text { Significant } \\
(\rho)\end{array}$} \\
\hline & Jasp & $26.46 \pm 1.98$ & $71.98 \pm 11.21$ & $\begin{array}{l}6 \text { cells; } \\
17866 \\
\text { tracks }\end{array}$ & \\
\hline \multicolumn{6}{|c|}{ System: Hypocotyl } \\
\hline \multirow[t]{4}{*}{$\begin{array}{l}\text { CLC2- } \\
\text { GFP }\end{array}$} & Mock & $10.43 \pm 0.43$ & $72.60 \pm 4.86$ & $\begin{array}{l}3 \text { cells; } \\
10883 \\
\text { tracks }\end{array}$ & \multirow[t]{2}{*}{ ns $(\tau ; \rho)$} \\
\hline & LatB & $10.02 \pm 0.73$ & $66.78 \pm 10.49$ & $\begin{array}{l}4 \text { cells; } \\
12623 \\
\text { tracks }\end{array}$ & \\
\hline & Mock & $11.37 \pm 0.27$ & $88.53 \pm 2.51$ & $\begin{array}{l}3 \text { cells; } \\
11132 \\
\text { tracks }\end{array}$ & \multirow[t]{2}{*}{ ns $(\tau ; \rho)$} \\
\hline & Jasp & $11.07 \pm 0.55$ & $77.97 \pm 10.71$ & $\begin{array}{l}3 \text { cells } \\
7876 \\
\text { tracks }\end{array}$ & \\
\hline
\end{tabular}




\begin{tabular}{|l|l|l|l|l|l|}
\hline \multirow{2}{*}{$\begin{array}{l}\text { TPLPTE- } \\
\text { GFP }\end{array}$} & Mock & $9.88 \pm 0.78$ & $97.50 \pm 16.98$ & $\begin{array}{l}4 \text { cells; } \\
13306 \\
\text { tracks }\end{array}$ & ns $(\tau ; \rho)$ \\
\cline { 2 - 5 } & LatB & $9.13 \pm 1.00$ & $84.84 \pm 11.42$ & $\begin{array}{l}3 \text { cells; } \\
12642 \\
\text { tracks }\end{array}$ & \\
\hline $\begin{array}{l}\text { Drp1C- } \\
\text { GFP }\end{array}$ & Mock & $16.76 \pm 0.64$ & $81.15 \pm 11.60$ & $\begin{array}{l}3 \text { cells; } \\
11004 \\
\text { tracks }\end{array}$ & ns $(\tau ; \rho)$ \\
\cline { 2 - 5 } & LatB & $14.57 \pm 1.57$ & $72.53 \pm 6.69$ & $\begin{array}{l}4 \text { cells; } \\
14658 \\
\text { tracks }\end{array}$ & \\
\hline
\end{tabular}

Supplementary table 1: The dynamics of CME EAPs on the PM during actin disruption.

The average lifetime and foci density of EAPs - CLC, TPLATE and Drp1C in both hypocotyl and root cells after $10 \mu \mathrm{M}$ LatB ( 1 - $1.5 \mathrm{~h}$ - hypocotyl and $10 \mathrm{~min}$ - root $)$ and $5 \mu \mathrm{M}$ Jasp (1.5 h-hypocotyl; $10 \mathrm{~min}$ - root) treatments. The mean $\pm \mathrm{SD}$ are specified. Two-sided unpaired $\mathrm{T}$ tests were performed to determine the effect of treatments. 